\title{
V2a Neurons Constrain Extradiaphragmatic Respiratory Muscle Activity at Rest
}

\author{
Victoria N. Jensen, ${ }^{1}$ Kari Seedle, ${ }^{2}$ Sarah M. Turner, ${ }^{2}$ John N. Lorenz, ${ }^{3}$ and ${ }^{\mathbb{S}}$ Steven A. Crone ${ }^{2,4,5}$ \\ https://doi.org/10.1523/ENEURO.0492-18.2019

\begin{abstract}
${ }^{1}$ Neuroscience Graduate Program, University of Cincinnati College of Medicine, Cincinnati, OH 45219, ${ }^{2}$ Division of Neurosurgery, Cincinnati Children's Hospital Medical Center, Cincinnati, OH 45229, ${ }^{3}$ Department of Pharmacology and Systems Physiology, University of Cincinnati College of Medicine, Cincinnati, OH 45267, ${ }^{4}$ Division of Developmental Biology, Cincinnati Children's Hospital Medical Center, Cincinnati, OH 45229, and ${ }^{5}$ Department of Neurosurgery, University of Cincinnati, College of Medicine, Cincinnati, OH 45267
\end{abstract}

\begin{abstract}
Breathing requires precise control of respiratory muscles to ensure adequate ventilation. Neurons within discrete regions of the brainstem produce oscillatory activity to control the frequency of breathing. Less is understood about how spinal and pontomedullary networks modulate the activity of respiratory motor neurons to produce different patterns of activity during different behaviors (i.e., during exercise, coughing, swallowing, vocalizing, or at rest) or following disease or injury. Here, we use a chemogenetic approach to inhibit the activity of glutamatergic V2a neurons in the brainstem and spinal cord of neonatal and adult mice to assess their potential roles in respiratory rhythm generation and patterning respiratory muscle activity. Using whole-body plethysmography (WBP), we show that V2a neuron function is required in neonatal mice to maintain the frequency and regularity of respiratory rhythm. However, silencing V2a neurons in adult mice increases respiratory frequency and ventilation, without affecting regularity. Thus, the excitatory drive provided by V2a neurons is less critical for respiratory rhythm generation in adult compared to neonatal mice. In addition, we used simultaneous EMG recordings of the diaphragm and extradiaphragmatic respiratory muscles in conscious adult mice to examine the role of V2a neurons in patterning respiratory muscle activity. We find that silencing V2a neurons activates extradiaphragmatic respiratory muscles at rest, when they are normally inactive, with little impact on diaphragm activity. Thus, our results indicate that V2a neurons participate in a circuit that serves to constrain the activity of extradiaphragmatic respiratory muscles so that they are active only when needed.
\end{abstract}

Key words: accessory respiratory muscle; diaphragm; electromyography; interneuron; respiration; V2a neuron

\section{Significance Statement}

Extradiaphragmatic respiratory muscles are crucial for increasing ventilation during exercise or following disease and injury, yet the neural mechanisms that ensure that they are recruited only when needed are not known. By silencing the activity of V2a neurons we reveal an important role for these neurons in preventing extradiaphragmatic respiratory muscle activity at rest. Unlike in neonatal mice, silencing V2a neurons in adult mice does not disrupt respiratory rhythm generation or have a major impact on diaphragm activity. Our results support the feasibility of targeting V2a containing circuits to control extradiaphragmatic muscles without impairing respiratory rhythm generation to treat patients with neuromuscular disease or spinal cord injury.

Received December 17, 2018; accepted June 17, 2019; First published July 19, 2019

The authors declare no competing financial interests.
Author contributions: V.N.J. and S.A.C. designed research; V.N.J., K.S., and S.M.T. performed research; J.N.L. contributed unpublished reagents/analytic tools; V.N.J. and K.S. analyzed data; V.N.J. and S.A.C. wrote the paper. 


\section{Introduction}

A major challenge in the study of respiratory control is to understand how different neurons modulate respiratory motor output to maintain ventilation during different behaviors, stages of development, or following disease and injury. For example, healthy mammals at rest rely predominantly on the diaphragm for inspiration. When ventilatory demands increase (i.e., during exercise), there is an increase in the activity of extradiaphragmatic respiratory muscles that include inspiratory pump muscles (e.g., external intercostal and scalenes) as well as accessory respiratory muscles (e.g., trapezius, pectoralis, and sternocleidomastoid; Sieck and Gransee, 2012) that we will refer to collectively as auxiliary respiratory muscles (ARMs). ARMs are also recruited in patients with neuromuscular disease, spinal cord injury, or diaphragm paralysis to compensate for impaired diaphragm function (Bennett et al., 2004; Sieck and Gransee, 2012; Johnson and Mitchell, 2013). However, it is not known why some patients with diaphragm impairment use ARMs more than others, as the neural mechanisms leading to recruitment of ARMs during exercise or following disease and injury are poorly understood. A better understanding of circuits patterning respiratory muscle activity would facilitate the development of therapies to improve ventilation, reduce respiratory infections, and prevent ventilation failure in patients with neuromuscular disease and injury.

The present study investigates the roles of V2a neurons, a class of glutamatergic neurons in the brainstem and spinal cord marked by Chx10 expression, in the control of respiratory rhythm and pattern in adult mice. A prior study showed that ablating V2a neurons during development results in slow and irregular breathing in neonates, likely due to a loss of excitatory drive from V2a neurons in the medial reticular formation to neurons in the pre-Bötzinger complex (Crone et al., 2012). However, these experiments could not conclusively distinguish whether the changes in breathing were the direct result of loss of V2a neuron function versus developmental defects resulting from the loss of V2a neurons in the embryo. In addition, a subset of these mice was able to survive past the neonatal period and their breathing pattern appears regular after the first week, indicating that V2a neurons might be dispensable for normal breathing in mature mice. Alternatively, ablation of V2a neurons in the embryo may lead to developmental compensation by other cell types to maintain ventilation in mature animals. Thus, it is

This work was supported by the National Institute of Neurologic Disorders and Stroke of the National Institutes of Health Grant T32NS5007453 (to V.N.J.) and by the McLaurin Fund (S.A.C.).

Acknowledgements: We thank Brooke Chastain and Omar Barazi for excellent technical assistance. All animal procedures were performed in accordance with Cincinnati Children's Hospital Medical Center animal care committee's regulations.

Correspondence should be addressed to Steven A. Crone at steven. crone@cchmc.org.

https://doi.org/10.1523/ENEURO.0492-18.2019

Copyright (C) 2019 Jensen et al.

This is an open-access article distributed under the terms of the Creative Commons Attribution 4.0 International license, which permits unrestricted use, distribution and reproduction in any medium provided that the original work is properly attributed. not yet clear whether V2a neuron function is critical for a normal respiratory rhythm in mature animals.

In addition to modulating respiratory rhythm and frequency, previous studies suggest that V2a neurons may be important for patterning respiratory muscle activity. Cervical spinal V2a neurons are synaptically connected to phrenic motor neurons and thus could modulate diaphragm function (Zholudeva et al., 2017). The number of V2a neurons connected to phrenic motor neurons increases following spinal cord injury, indicating that V2a neurons may be particularly important for respiratory compensation following injury. In addition, it has been suggested that degeneration of V2a neurons in a mouse model of ALS could account for the failure of accessory respiratory muscles to be activated for breathing at late stages of disease (Romer et al., 2017). This hypothesis was based on the observation that increasing the excitability of V2a neurons using an excitatory designer receptors exclusively activated by designer drugs (DREADD) in healthy adult mice activates scalene and trapezius respiratory muscles at rest, when these muscles are mostly inactive (Romer et al., 2017). Thus, V2a neurons have the potential to influence the number and type of respiratory motor neurons recruited for breathing. However, it is not yet known whether $\mathrm{V} 2 \mathrm{a}$ neural activity is required for patterning respiratory motor activity in adult mice.

Here, we target expression of an inhibitory DREADD (hM4Di or " $\left(\mathrm{G}_{\mathrm{i}}\right)$ DREADD"; Urban and Roth, 2015) to Chx10 expressing neurons to test whether normal activity of V2a neurons is required for a regular breathing rhythm and frequency in healthy neonatal and adult mice and to evaluate their role in patterning activity of respiratory muscles in adult mice. We find that the activity of V2a neurons is important for modulating the frequency and regularity of respiratory rhythm in neonatal mice, but only modulates the frequency of respiration in adult mice. In addition, we show that silencing $\mathrm{V} 2 \mathrm{a}$ neurons results in activation of ARMs in adult mice at rest, suggesting that these neurons play an important role in patterning extradiaphragmatic respiratory muscle activity.

\section{Materials and Methods}

\section{Animals}

All animal procedures were performed according the National Institutes of Health guidelines and approved by the institution's animal care committee's regulations. V2a- $\left(G_{i}\right) D R E A D D$ mice were generated by breeding Chx10 $\mathrm{Cre/+}$ mice (Azim et al., 2014; Romer et al., 2017) to ROSA $^{\text {PNP-(Gi)DREADD/+ }}$ (B6N.129-Gt(ROSA)26Sortm1 (CAG-CHRM4*, -mCitrine)Ute/JJax, stock \#026219, The Jackson Laboratory) mice to generate $\mathrm{Ch} \times 10^{\mathrm{Cre} /+}$; $\mathrm{ROSA}^{\mathrm{PNP}-(\mathrm{Gi}) \mathrm{DREADD} /+}$ mice. Adult male $\mathrm{Ch} \times 10^{\mathrm{Cre} /+}$ mice (lacking the ROSA ${ }^{\text {PNP-(Gi)DREADD/+ }}$ allele) were used as non-DREADD expressing controls. On rare occasions, we observe recombination outside of the nervous system as a result of "leaky" germline or early embryo expression of Cre recombinase. Therefore, we perform PCR on DNA isolated from the tail of all animals to identify any with the recombined $\mathrm{ROSA}^{\mathrm{P}-(\mathrm{Gi}) \mathrm{DREADD} /+}$ allele and these animals are excluded from all experiments and breeding (primers: 
5'-CTCTG CTAAC CATGT TCATG C-3' and 5'-GAAGG CGCCT ATGAT GAGAT C-3'). Genotyping was performed by PCR using primers to detect the Chx10 $10^{\text {Cre }}$ (5'-GCATT AGACA CCGGA GGG-3' and 5'-GGACA GAAGC ATTाT CCAG-3'), Chx10 wild type (5'-GCATT AGACA CCGGA GGG-3' and 5'CTCCC GACTG TGACT TTCC-3'), ROSA PNP-(Gi)DREADD (5'ATGTC TGGAT CCCCA TCAAG-3' and 5'-GAAGG CGCCT ATGAT GAGAT C-3') and ROSA wild type (5'-AAGGG AGCTG CAGTG GAGTA-3' and 5'-GAAAA TCTGT GGGAA GTC-3') alleles.

\section{Histology, imaging, and quantification}

Immunohistochemical and imaging analysis was performed on spinal cords and medulla of neonatal and adult V2a$\left(G_{i}\right) D R E A D D$ mice. Specificity of the HA antibody was confirmed by lack of staining in $\mathrm{Ch} \times 10^{\mathrm{Cre} /+}$ and ROSA ${ }^{\mathrm{PNP}-\mathrm{CHRM} 4 /+}$ mice that lack expression of the HA-tagged $\left(G_{i}\right) D R E A D D$. Neonatal mice were placed on ice for 4 min and transcardially perfused with $4 \%$ paraformaldehyde (PFA) in phosphate buffer (PB; $770 \mathrm{mM} \mathrm{Na} \mathrm{HPO}_{4} \cdot 7 \mathrm{H}_{2} \mathrm{O}$, and $231 \mathrm{mM}$ $\mathrm{NaH}_{2} \mathrm{PO}_{4} \cdot \mathrm{H}_{2} \mathrm{O}, \mathrm{pH}$ 7.4). Brains and spinal cords were dissected and submerged in 4\% PFA until $2 \mathrm{~h}$ after the start time of perfusion. Tissue was then rinsed in phosphate PBS (137 mM NaCl, $2.7 \mathrm{mM} \mathrm{KCl}, 10 \mathrm{mM} \mathrm{Na}_{2} \mathrm{HPO}_{4}$, and $2 \mathrm{mM} \mathrm{KH}_{2} \mathrm{PO}_{4}, \mathrm{pH}$ 7.2) overnight to remove PFA, cryoprotected in $30 \%$ sucrose overnight (all at $4^{\circ} \mathrm{C}$ ), mounted in OCT medium and stored at $-80^{\circ} \mathrm{C}$. Transverse sections of cervical spinal cord and medulla were cut $(14 \mu \mathrm{m})$ on a cryostat microtome and collected directly onto slides. Immunohistochemistry was performed as described previously (Thaler et al., 1999; Crone et al., 2009) using the following primary antibodies (and DAPI nuclear stain): Chx10 (guinea pig at 1:10,000), and HATag C29F4 (rabbit at 1:1000, Cell Signaling \#3724). Images were obtained on a Nikon A1 Plus inverted confocal microscope. The number of $\mathrm{HA}-\mathrm{Tag}^{+}, \mathrm{Ch} \times 10^{+}$, and HA$\mathrm{Tag}^{+} / \mathrm{Ch} \times 10^{+}$cells with DAPI ${ }^{+}$nuclei were counted from single plane confocal $20 \times$ images using NIS Elements Software. Every forth section at C4 (16-18 hemisections/ animal) was counted for cervical sections and every forth section at the level of the nucleus ambiguous for medulla sections (18-20 hemisections/animal). The average number of cells per hemisection was calculated for each animal. C4 was used as a standard reference point based on the distinct morphology of the phrenic nucleus in this segment to ensure counts were made at a consistent axial level. Similarly, the distinct morphology of the nucleus ambiguous was used as a reference in the medulla.

Adult mice were anesthetized with pentobarbital $(0.1$ $\mathrm{mg} / \mathrm{g}$, i.p.) and were transcardially perfused with $\mathrm{PB}$ followed by $4 \%$ PFA in PB. Tissue was rinsed in PBS overnight, cryoprotected in 30\% sucrose overnight (all at $4^{\circ} \mathrm{C}$ ), mounted in OCT medium and stored at $-80^{\circ} \mathrm{C}$. Transverse sections of adult cervical spinal cords were cut $(14 \mu \mathrm{m})$ on a cryostat microtome and collected directly onto slides. Transverse sections of adult medulla were cut $(50 \mu \mathrm{m})$ on a cryostat microtome and collected as floating sections in PBS $+30 \% \mathrm{v} / \mathrm{v}$ ethylene glycol + $25 \% \mathrm{w} / \mathrm{v}$ glycerol. Immunohistochemistry was performed on adult tissue as described previously (Romer et al.,
2017) using the following primary antibodies (and DAPI nuclear stain): Chx10 (sheep at 1:2000, Abcam \#ab16141), and HA-Tag C29F4 (rabbit at 1:1000, Cell Signaling \#3724). The number of $\mathrm{HA}-\mathrm{Tag}^{+}$cells, $\mathrm{Ch} \times 10^{+}$cells, and $\mathrm{HA}-\mathrm{Tag}^{+} /$ Ch $\times 10^{+}$cells with DAPI ${ }^{+}$nuclei were counted as described above in every eighth section at C4 (9-14 hemisections/ animal) and in every third section at the level of the nucleus ambiguous (12-13 hemisections/animal). The average number of cells per hemisection was calculated for each animal.

\section{Surgical implantation of telemetry devices}

Telemetry devices [either single (TAE-F10) or double channel (F20-EET) transmitters from Data Sciences International] were implanted as early as eight weeks of age to chronically record EMG from respiratory muscles of V2a$\left(G_{i}\right) D R E A D D$ and non-DREADD control mice. Surgeries to implant devices subcutaneously for recording EMG from the trapezius and scalene muscles were performed as previously described (Jensen et al., 2017; Romer et al., 2017). Briefly, a 3-cm-long incision was made between the right shoulder and ear and the transmitter was placed subcutaneously on the back of the mouse. Two sets of biopotential leads were inserted $\sim 1 \mathrm{~mm}$ apart from one another into the trapezius and scalene muscles. The incision was closed and mice were allowed to recover for one week before recording.

Surgeries to implant devices intraperitoneally to record EMG from diaphragm and/or trapezius muscles were performed as follows. Mice were placed supine under isoflurane anesthesia. A "T" incision was made in the skin by making a 4-cm-long lateral incision directly below the xyphoid process and an adjoining 2-cm-long vertical incision was made from the middle of the lateral incision to the middle of the rib cage. Next, a 3-cm-long lateral incision was made through the abdomen muscle just below the rib cage. The xyphoid process was clamped with Hemostats to expose the diaphragm. The transmitter was placed on the left side of the abdominal cavity next to the intestines. One set of leads was set aside for later use (trapezius insertion) while the other set was positioned near the diaphragm. Forceps were used to gently lift up on the right side of the costal diaphragm. Forceps were used to insert the exposed wire of one biopotential lead through the first muscle layer of the diaphragm muscle without puncturing the second muscle layer. Extreme care was taken to ensure that the diaphragm was not punctured to prevent a fatal injury. The exposed wire was secured in place against the diaphragm muscle with a small drop of cyanoacrylate adhesive. A second biopotential lead was inserted in the same manner $\sim 1 \mathrm{~mm}$ caudal to the position of the first lead. Excess lead length was coiled and placed just below the abdominal muscle and above the implanted transmitter. The abdominal muscle was closed over the transmitter and excess coiled leads with suture, with care taken to externalize the second pair of biopotential leads for trapezius insertion. The skin incision was closed using inside out sutures, leaving $\sim 1 \mathrm{~mm}$ open closest to the mouse' head where the second set of leads remained exposed. A second incision 
was made between the mouse' right shoulder and ear to expose the trapezius muscle. A trocar was used to tunnel the second set of exposed leads subcutaneously from the intraperitoneally implanted transmitter to the open incision near the mouse' shoulder. The leads were inserted into the trapezius muscle as described above. Mice were allowed to recover for one to two weeks before EMG data acquisition.

\section{Neonatal whole-body plethysmography (WBP)}

WBP was performed on age P2 non-DREADD expressing mice and V2a-(Gi)DREADD mice. The barometric chambers were standardized by injecting 10 consecutive 10- $\mu$ l pumps of air into an open port on the experimental chamber using a 100- $\mu$ l Hamilton syringe. Animals were placed in a barometric chamber and equilibrated with open air flow for $5 \mathrm{~min}$. The pressure difference between the sealed experimental and reference chambers was measured with a differential pressure transducer for two 60s recording sessions: one baseline session and one session 20 min after an intraperitoneal injection of $10 \mu \mathrm{l}$ of $10.0 \mathrm{mg} / \mathrm{kg}$ bw clozapine-N-oxide (CNO). Data are expressed in relative units (R.U.) normalized to the average maximum value obtained during standardization with 10- $\mu$ l pumps of air from a syringe. CNO solutions were made by dissolving CNO directly into saline. At least 10 min of open-air flow was allowed between trials. Signals were amplified, digitized, and low pass filtered $(50 \mathrm{~Hz})$. Data were collected and analyzed using LabChart 7.0 software (AD Instruments).

\section{Neonatal plethsymography analysis}

LabChart 7.0 software (AD Instruments) was used to mark individual resting breaths to be analyzed for breathing frequency. At least 70 resting breaths were analyzed before and after $\mathrm{CNO}$ administration. An irregularity score (IS $\left.=\operatorname{ABS}\left[\left(T_{n}-T_{(n-1)}\right) / T_{(n-1)}\right] * 100\right)$ was calculated for each breath (Viemari et al., 2011; Sheikhbahaei et al., 2017). The average IS of at least 50 consecutive breaths for each animal under each condition (without and with $\mathrm{CNO}$ ) is reported. Breaths during movement were excluded from analysis.

\section{Adult WBP and EMG acquisition in conscious animals}

Plethysmography, EMG acquisition, and digital video recording was performed as described previously (Jensen et al., 2017; Romer et al., 2017) using DSI Ponemah Physiology Platform Acquisition software v.5.20. Briefly, mice were placed in a plethysmography chamber on top of a transmitter receiving pad and allowed to acclimate for $30 \mathrm{~min}$. The transmitter was turned on by placing a strong magnet near the animal inside the chamber before data collection. A vehicle control $(0.1 \mathrm{ml}$ of saline) was injected IP. Mice were placed in their home cage for 2 min immediately following all injections before being placed into the plethysmography chamber to prevent association of a painful injection with the chamber. After 2 min of reacclimating to the chamber, the transmitter was turned on and at least 20 min of resting data were collected (characterized by mouse inactivity and regular breathing). Next, mice were injected intraperitoneally with either 1.0, 5.0, 10.0 , or $15.0 \mathrm{mg} / \mathrm{kg}$ bw CNO, placed in their home cage for $2 \mathrm{~min}$, and then reacclimated to the chamber for $2 \mathrm{~min}$ before data acquisition began for $1 \mathrm{~h}$. The same animals were tested with multiple CNO doses, with at least $2 \mathrm{~d}$ between each dose to avoid desensitization of DREADD receptors. A vehicle control recording was performed before each dose of CNO. Only periods in which the animal is at rest (not moving in video recordings) are used for analysis.

\section{Adult plethysmography analysis}

The Ponemah Physiology Platform Analysis software v.5.20 was used to mark individual resting breaths to be analyzed for breathing frequency $(f)$, tidal volume $\left(V_{T}\right)$, minute volume (MV), peak inspiratory flow (PIF), inspiratory time $\left(\mathrm{T}_{\mathrm{i}}\right)$, expiratory time $\left(\mathrm{T}_{\mathrm{e}}\right)$, and total breathing cycle time $\left(T_{t}\right)$ as described previously (Jensen et al., 2017; Romer et al., 2017). $V_{T} / T_{i}$, a measure of respiratory drive, was calculated from these derived values. Periods of ARM activity (trapezius bouts) were identified as described above. Interbout intervals used for analysis excluded all bouts as well as the four breaths immediately preceding or following a bout. At least 100 resting breaths were analyzed for each vehicle control and CNO treatment period. The average IS of 100 consecutive breaths (the same breaths analyzed for ventilation parameters) for each animal under each condition (vehicle or $\mathrm{CNO}$ ) is reported.

\section{EMG analysis in conscious animals}

The raw EMG signal was high pass filtered at $1.5 \mathrm{~Hz}$ and the root mean square (RMS) was calculated using a 30-ms window. The frequency of bouts of trapezius or scalene activity was counted as described previously (Jensen et al., 2017). Briefly, ARM EMG activity is scored as a "bout" if it satisfies the following three criteria: (1) the RMS EMG trace must exhibit at least three consecutive points that are at least $50 \%$ higher than the surrounding baseline (each point represents a $30-\mathrm{ms}$ window), (2) EMG activity occurs during resting breaths (i.e., sighs and movement artifacts are excluded), and (3) EMG activity occurs when the mouse is still (i.e., no movement or changes in posture) based on the synchronized video recordings. ARM bout frequency was calculated by dividing the total number of bouts observed by the total time analyzed. Interbout intervals used for analysis excluded all bouts as well as the four breaths immediately preceding or following a bout. For analysis of diaphragm EMG, the RMS was used to measure the peak amplitude, duration, and instantaneous frequency of each breath (burst of activity). Diaphragm EMG peak amplitude was normalized to the maximum ventilatory effort reached during sighs to reduce intra-animal variability (Mantilla, et al., 2011). At least 50 resting breaths were analyzed for each vehicle control and CNO treatment period.

\section{Diaphragm EMG acquisition in anesthetized animals}

Terminal bilateral diaphragm EMG recordings were performed on adult V2a-(Gq)DREADD and V2a-(Gi)DREADD mice before and after CNO administration. Animals were 
Table 1. Summary of statistical analyses

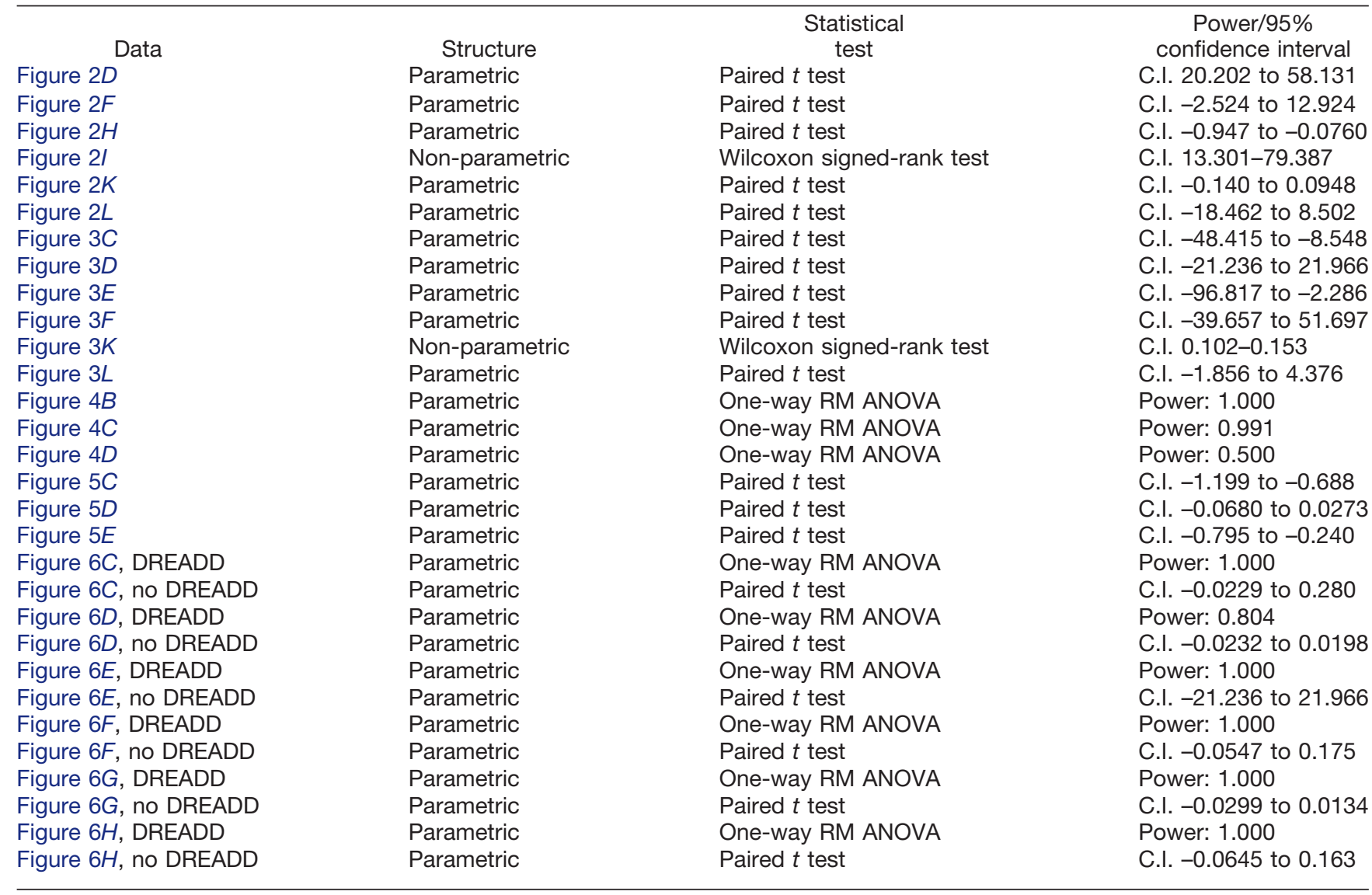

anesthetized under isoflurane anesthesia and placed supine on a heating pad. A 4-cm lateral incision through the skin and abdominal muscle just below the xyphoid process exposed the intraperitoneal cavity and diaphragm. Bi-polar platinum electrodes (Grass Technology) connected to an amplifier (BMA-400 AC/DC Bioamplifier, CWE Inc.) were inserted into the diaphragm and secured with cyanoacrylate adhesive to record diaphragmatic activity via Spike2 Data Analysis software (Cambridge Electronic Design Limited). Electrodes were grounded with an additional lead inserted into the abdominal muscle. A 10-min baseline of bilateral diaphragm activity was recorded. CNO was then topically applied to the exposed intraperitoneal cavity and diaphragm EMG was recorded for $1 \mathrm{~h}$.

\section{EMG analysis in anesthetized animals}

The diaphragm EMG signal was digitally amplified $(5000 \times$ gain) and band pass filtered $(30-3000 \mathrm{~Hz})$ with a sampling frequency of $6.25 \mathrm{kHz}$. EMG signals were further processed to remove DC noise and the RMS was calculated over a 30-ms window. ECG artifact was digitally filtered out using the ECGDelete02 Spike2 script (Cambridge Electronic Design). Diaphragm EMG peak amplitude was normalized to the maximum ventilatory effort reached during sighs to reduce intra-animal variability (Mantilla, et al., 2011). At least 50 bursts were analyzed for diaphragm EMG peak amplitude and regularity of bursting frequency for the baseline recording and following CNO treatment.

\section{Statistical analysis}

Statistical tests from SigmaStat 13 (Systat Software, SPSS Inc.) were used to analyze the data (see Table 1). All data passed the Shapiro-Wilk test for normality, except as noted. A one-way repeated measures ANOVA (Holm-Sidak all pairwise comparisons post hoc analysis) was used to analyze differences within animals when comparing values from three or more conditions tested within the same animal (e.g., multiple doses of CNO on ARM recruitment). Paired $t$ tests were used to analyze differences in treatments within the same animal where only two conditions existed (e.g., vehicle vs CNO). Student $t$ tests were used to analyze differences between groups (e.g., V2a-(G)DREADD vs $\mathrm{Ch} \times 10^{\mathrm{Cre} /+}$ mice). Non-parametric Wilcoxon signed-rank tests were performed on datasets that failed the test for normality (coefficient of variation of breathing frequency $\left(\mathrm{CV}_{\mathrm{f}}\right)$ and irregularity score (IS) between vehicle control and CNO-treated conditions). Statistical significance was set at alpha level 0.05 , and values in figures are reported as mean \pm SE.

\section{Results}

\section{$\left(G_{i}\right)$ DREADD is expressed in $\mathbf{V} 2 a$ neurons in the} spinal cord and brainstem of V2a- $\left(G_{i}\right)$ DREADD mice

To test the role of $\mathrm{V} 2 \mathrm{a}$ neurons in modulating respiratory rhythm and motor pattern, we generated V2a$\left(\mathrm{G}_{\mathrm{i}}\right)$ DREADD mice $\left(\mathrm{Ch} \times 10^{\mathrm{Cre} /+}\right.$; ROSA $\left.\mathrm{RNP}^{\mathrm{P}(\mathrm{Gi}) \mathrm{DREADD} /+}\right)$ to decrease the excitability of $\mathrm{V} 2 \mathrm{a}$ neurons following acute 
injections of CNO (Urban and Roth, 2015; Zhu et al., 2016). Ch $\times 10^{\mathrm{Cre} /+}$ mice, in which Cre recombinase has been inserted into the endogenous Chx10 locus by homologous recombination, have previously been used to reliably drive reporter gene expression in V2a neurons that express Chx10 during development or in the adult (Azim et al., 2014; Bouvier et al., 2015; Romer et al., 2017; Hayashi et al., 2018). Viruses expressing the (Gi)DREADD receptor have previously been used to inhibit $\mathrm{V} 2 \mathrm{a}$ neuron activity in spinal neurons to assess their role in fine motor control (Ueno et al., 2018), but breathing was not assessed in this study. We used antibodies to the hemagglutinin tag (HA-Tag) on the $\left(\mathrm{G}_{\mathrm{i}}\right) \mathrm{DREADD}$ receptor and antibodies to Chx10 to mark the nuclei of V2a neurons to assess the distribution of $\left(\mathrm{G}_{\mathrm{i}}\right) \mathrm{DREADD}$ in the cervical spinal cord (C4) and medulla of neonatal and adult V2a$\left(G_{i}\right)$ DREADD mice (Fig. 1). The pattern of $\left(G_{i}\right)$ DREADD expression is similar in neonatal (postnatal day 2) and adult animals. $\mathrm{HA}-\mathrm{Tag}^{+}$cells have neuronal morphology and are located where V2a neurons are found: the intermediate laminae (but not dorsal horn) of the spinal cord and medial reticular formation of the medulla, consistent with prior studies using $\mathrm{Ch} \times 10^{\mathrm{Cre} /+}$ mice to selectively drive reporter expression in V2a neurons (Azim et al., 2014; Bouvier et al., 2015; Romer et al., 2017; Hayashi et al., 2018). We detected HA-Tag ${ }^{+}$immunoreactivity in an average of $24.1 \pm 0.6(n=5), 11.1 \pm 0.4(n=6), 100.6$ $\pm 10.9(n=3)$, and $112.9 \pm 7.5(n=3)$ cells/hemisection in neonatal spinal cord, adult spinal cord, neonatal medulla, and adult medulla, respectively, of $\mathrm{V} 2 \mathrm{a}-\left(\mathrm{G}_{\mathrm{i}}\right) \mathrm{DREADD}$ mice. This represents $77 \pm 0.8 \%$ of $\mathrm{Ch} 10^{+}$neurons in neonatal and $80 \pm 1.3 \%$ of $\mathrm{Chx} 10^{+}$neurons in adult cervical cord. In the medulla (at the level of the nucleus ambiguous) we detect $\mathrm{HA}-\mathrm{Tag}^{+}$immunoreactivity in 65 $\pm 4 \%$ of $C h \times 10^{+}$neurons in neonatal and $58 \pm 3 \%$ of Chx $10^{+}$neurons in adult V2a- $\left(G_{i}\right)$ DREADD mice. HA$\mathrm{Tag}^{+}$cells are not observed in mice lacking the ROSA $^{\text {PNP-(Gi)DREADD/+ }}$ allele in P2 neonates $(n=5)$ or adults $(n=4)$, confirming the specificity of our antibody. As expected from prior studies showing that $\sim 50 \%$ of V2a neurons in the cervical cord that express Chx10 during embryonic development have low (detectable by RNA sequencing but undetected by antibodies) Chx10 expression after birth (Hayashi et al., 2018), we found that $47 \pm 2 \%$ of $\mathrm{HA}-\mathrm{Tag}^{+}$neurons of P2 neonatal mice did not express detectable levels of Chx10. Similarly, $35 \pm 6 \%$ of $\mathrm{HA}-\mathrm{Tag}^{+}$ cells in neonatal medulla, $23.3 \pm 3 \%$ in adult cervical spinal cord, and $23 \pm 3 \%$ in adult medulla do not express detectable levels of Chx10. These results demonstrate that V2a$\left(G_{i}\right) D R E A D D$ mice express the inhibitory DREADD receptor in the majority of V2a neurons and the extent and pattern of expression is similar in neonatal and adult mice.

\section{Decreasing the excitability of V2a neurons results in slow and irregular breathing in V2a-( $\left.\mathrm{G}_{\mathrm{i}}\right)$ DREADD neonatal mice}

Previous experiments in which V2a neurons were ablated during embryonic development could not conclusively distinguish if the changes in breathing were the direct result of loss of V2a neuron function versus devel- opmental defects resulting from the loss of V2a neurons in the embryo. Therefore, we used whole body plethysmography (WBP) to measure respiratory frequency and regularity in postnatal day $2 \mathrm{~V} 2 \mathrm{a}-\left(\mathrm{G}_{\mathrm{i}}\right) \mathrm{DREADD}$ mice before and after CNO treatment to determine the effects of acutely silencing V2a neurons on breathing (Fig. 2). The number of respiratory cycles/min was calculated before and after CNO treatment in both V2a- $\left(G_{i}\right)$ DREADD mice and littermate non-DREADD expressing controls. Decreasing the excitability of V2a neurons slowed the respiratory rate from $91.3 \pm 4.3$ to $53.5 \pm 3.1$ cycles $/ \min (n=6, p=$ 0.023 ; Fig. $2 D$ ) whereas no change was observed in nonDREADD controls (before CNO: $99.2 \pm 5.1 \mathrm{cycles} / \mathrm{min}$ vs after CNO $94.0 \pm 5.3$ cycles $/ \mathrm{min}, n=5, p=0.135$; Fig. $2 F$. There is no significant difference in the respiratory rate between $\mathrm{V} 2 \mathrm{a}-\left(\mathrm{G}_{\mathrm{i}}\right) \mathrm{DREADD}$ mice and controls before administration of CNO $(p=0.308)$.

To examine breath-to-breath consistency of the breathing frequency, we plotted the instantaneous frequency for at least 50 consecutive breaths before and after 10.0 $\mathrm{mg} / \mathrm{kg}$ bw CNO treatment. V2a-(Gi) DREADD mice injected with CNO showed a highly variable breathing frequency (Fig. 2C) that was not seen in CNO-treated non-DREADD controls (Fig. 2E). In addition, we generated Poincare maps by plotting the breathing period $(T n)$ versus the subsequent period $\left(T_{n+1}\right)$. When breathing is consistent, the points in a Poincare plot form a tight cluster (Del Negro et al., 2002; Crone et al., 2012), as seen in non-DREADD controls before and after administration of CNO (Fig. 2J). In contrast, decreasing the excitability of V2a neurons in neonatal V2a- $\left(G_{i}\right)$ DREADD mice resulted in disperse Poincare maps (Fig. $2 G$ ), indicating that breathing period fluctuates from breath to breath, similar to mice in which V2a neurons are ablated (Crone et al., 2012). To further quantify the regularity of breathing in $\mathrm{V} 2 \mathrm{a}-\left(\mathrm{G}_{\mathrm{i}}\right) \mathrm{DREADD}$ mice, we compared the $\mathrm{CV}_{f}$ in each animal before and after CNO treatment. We also calculated the IS, which has previously been used to measure changes in respiratory rhythm regularity in medullary slices treated with pharmacological agents and whole animals following carotid body ablation (Viemari et al., 2011; Sheikhbahaei et al., 2017). The $C_{\mathrm{f}}$ and IS were both significantly increased following CNO treatment in $\mathrm{V} 2 \mathrm{a}-\left(\mathrm{G}_{\mathrm{i}}\right) \mathrm{DREADD}$ mice $\left(\mathrm{CV}_{\mathrm{f}}\right.$ : $0.22 \pm 0.03$ vehicle vs $0.73 \pm 0.15 \mathrm{CNO}, p=0.030, n=$ 6 ; IS: $19.22 \pm 2.79 \%$ vehicle vs $68.81 \pm 19.40 \% \mathrm{CNO}, p$ $=0.031, n=5$; Fig. $2 H, l)$. This is compared to no change observed in non-DREADD expressing control mice $\left(\mathrm{CV}_{\mathrm{f}}\right.$ : $0.23 \pm 0.03$ vehicle vs $0.26 \pm 0.02 \mathrm{CNO}, p=0.619, n=$ 6 IS: $16.67 \pm 3.31 \%$ vehicle vs $21.65 \pm 3.31 \%$ CNO, $p=$ $0.363, n=5$; Fig. $2 K, L)$. No fatalities occurred in either genotype following CNO treatment, despite the occurrence of apneas in V2a-(Gi)DREADD pups. Thus, V2a neuron activity is required to maintain both the frequency and regularity of breathing in neonatal mice.

\section{Decreasing V2a neuron excitability increases breathing frequency without altering regularity in adult mice}

We next assessed whether acutely silencing V2a neurons in adult mice alters the frequency or regularity of 

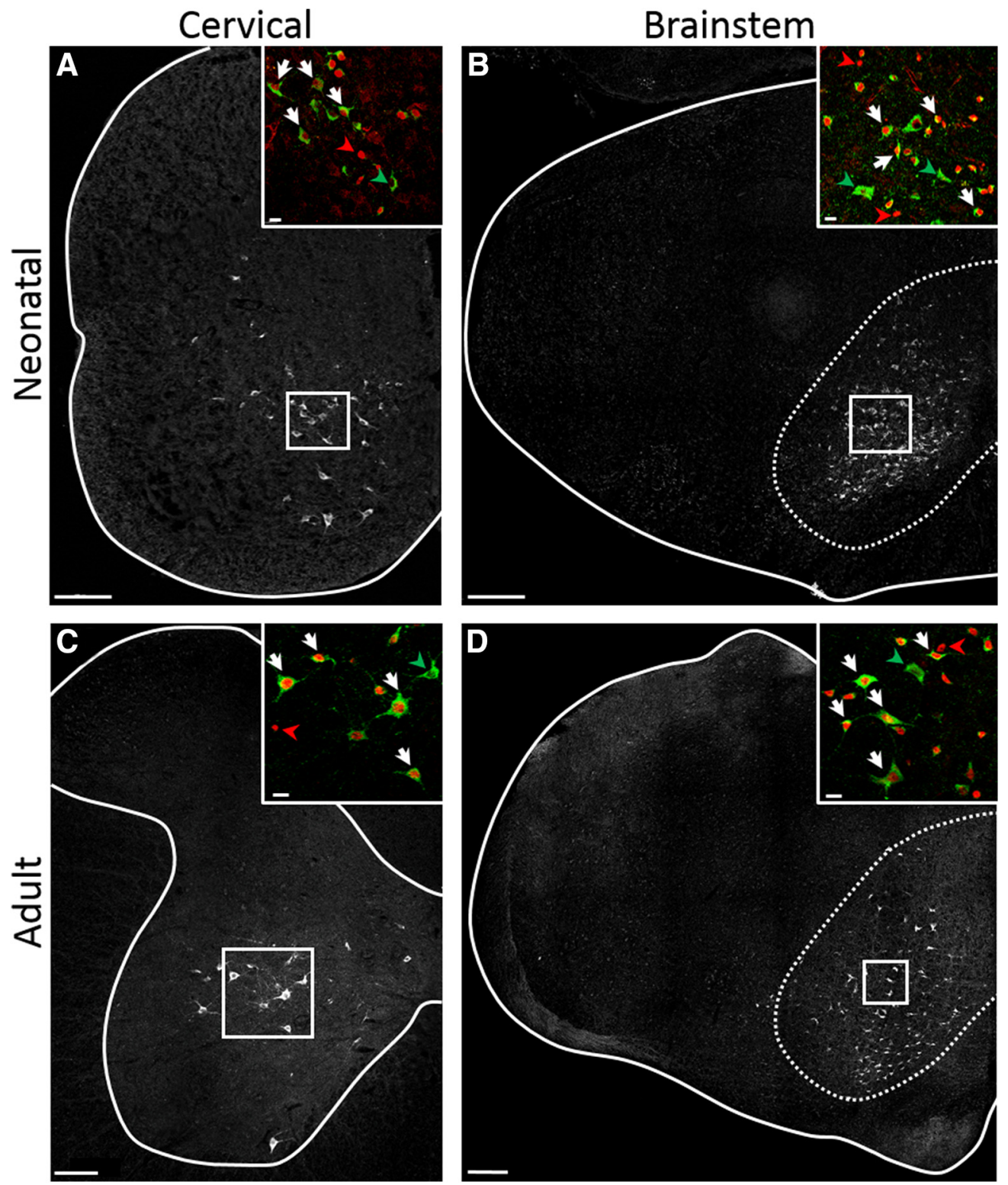

Figure 1. $\left(\mathrm{G}_{\mathrm{i}}\right) \mathrm{DREADD}$ is expressed in V2a neurons in the spinal cord and brainstem of $\mathrm{V} 2 \mathrm{a}-\left(\mathrm{G}_{\mathrm{i}}\right) \mathrm{DREADD}$ mice. Immunohistochemistry using antibodies to $\mathrm{Chx} 10$ and the HA tag on $\left(G_{i}\right)$ DREADD were used to label the nuclei of V2a neurons and $\left(G_{i}\right) D R E A D D$ expressing cells, respectively, in V2a- $\left(\mathrm{G}_{\mathrm{i}}\right) \mathrm{DREADD}$ mice. $\boldsymbol{A}$, C4 cervical spinal cord section (spinal cord boundary outlined) of a neonatal (P2) mouse showing $\left(G_{i}\right)$ DREADD expression in the intermediate lamina where V2a neurons are found. Scale bar $=100 \mu \mathrm{m}$. $\boldsymbol{B}$, Coronal section of the medulla of a neonatal (P2) mouse at the level of the nucleus ambiguous showing $\left(G_{i}\right) D R E A D D$ expression in the medial reticular formation outlined (dotted line) where V2a neurons are found. Scale bar $=200 \mu \mathrm{m}$. C, C4 cervical spinal cord section (gray matter outlined) of an adult mouse showing $\left(G_{i}\right) D R E A D D$ expression in the intermediate lamina where V2a neurons are found. Scale bar $=100 \mu \mathrm{m}$. $\boldsymbol{D}$, Coronal section of the medulla of an adult mouse at the level of the nucleus ambiguous showing $\left(\mathrm{G}_{\mathrm{i}}\right) \mathrm{DREADD}$ expression in the medial reticular formation outlined (dotted line) where V2a neurons are found. Scale bar $=200 \mu \mathrm{m}$. Insets, Boxed

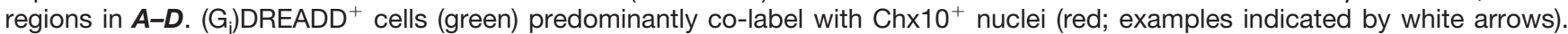
Chx $10^{+}$neurons without $\left(G_{i}\right)$ DREADD expression (examples indicated by red arrowheads) and $\left(G_{i}\right)$ DREADD cells without detectable $\mathrm{Chx} 10^{+}$(examples indicated by green arrowheads) are infrequently observed. Scale bars $=20 \mu \mathrm{m}$.

breathing. Following intraperitoneal injection of either vehicle or CNO, V2a- $\left(G_{i}\right)$ DREADD mice $(n=9)$ were placed in a plethysmography chamber to measure ventilation. A subset of V2a-(Gi)DREADD mice (four of the nine) were instrumented with telemetry devices to record EMG from the diaphragm. A representative trace showing simultaneous recordings of WBP and diaphragm EMG following vehicle and CNO injections is shown in Figure $3 A, B$. Instantaneous breathing frequency (f) was measured from plethysmography recordings taken before and after CNO treatment $(n=9)$. Surprisingly, silencing V2a neurons in adult mice increased respiratory frequency 15.3\% (Fig. $3 C)$, whereas no change was observed in the control mice lacking the $\left(\mathrm{G}_{\mathrm{i}}\right) \mathrm{DREADD}$ receptor $(0.2 \pm 4.5 \% ; p=1.00$, 
A
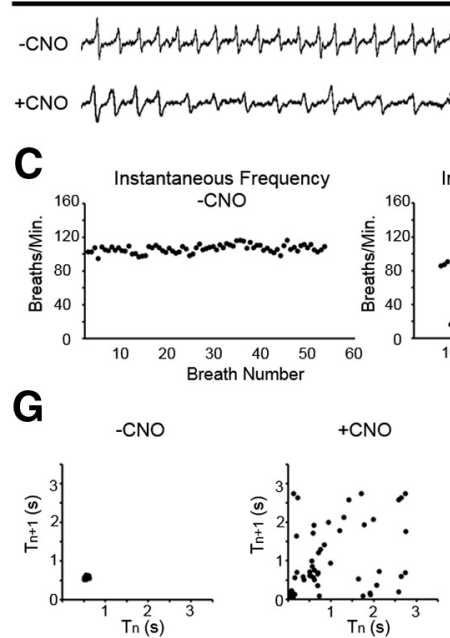

V2a-(Gi)DREADD

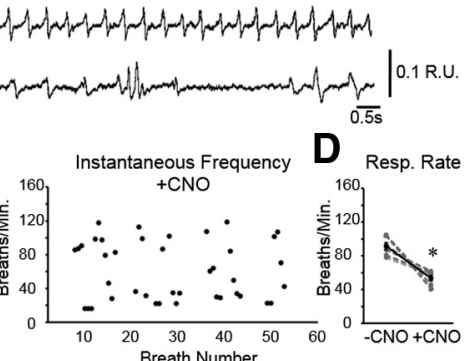

B

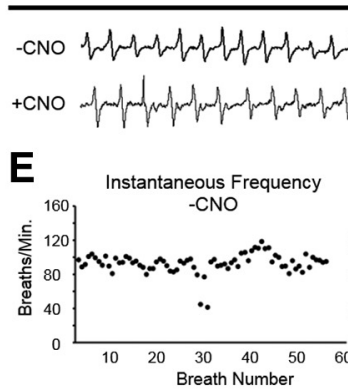

J

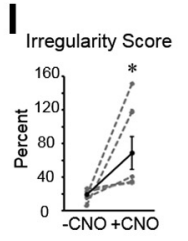

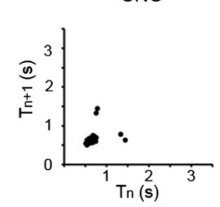

Non-DREADD Control

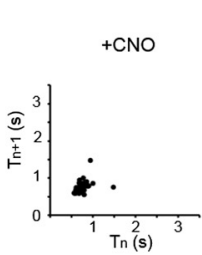

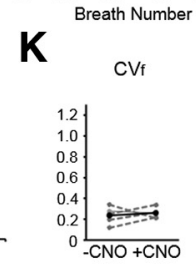

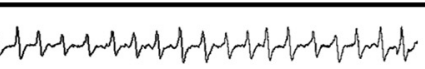
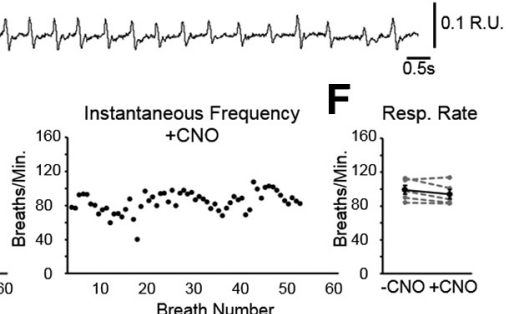

L

Irregularity Score

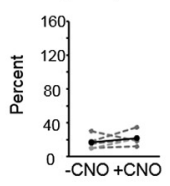

Figure 2. Decreasing the excitability of V2a neurons causes irregular breathing in neonatal V2a-(G)DREADD mice. Representative traces of WBP before (top trace) and after (bottom trace) $10.0 \mathrm{mg} / \mathrm{kg}$ bw CNO treatment in a (A) V2a-G $($ (DREADD) mouse and a $(\boldsymbol{B})$ non-DREADD control $\left(\mathrm{Ch} \times 10^{\mathrm{Cre} /+}\right)$ mouse at P2. $\boldsymbol{C}, \boldsymbol{E}$, Instantaneous respiratory frequency is plotted for at least 50 consecutive breaths in V2a- $\left(\mathrm{G}_{\mathrm{i}}\right) \mathrm{DREADD}$ mice and non-DREADD control mice before (left) and after (right) CNO treatment to illustrate the breath to breath consistency of respiratory frequency. $\boldsymbol{D}, \boldsymbol{F}$, Respiratory rate is decreased after silencing $\mathrm{V} 2 \mathrm{a}$ neurons in $\mathrm{V} 2 \mathrm{a}-\left(\mathrm{G}_{\mathrm{i}}\right)$ DREADD mice but remains unchanged following CNO treatment in non-DREADD control mice. Poincare maps generated by plotting the respiratory cycle period $\left(T_{n}\right)$ versus the subsequent respiratory cycle period $\left(T_{n+1}\right)$ from the same trials shown in $\boldsymbol{C}, \boldsymbol{E}$ show an inconsistent period following CNO treatment in $V 2 a-\left(G_{i}\right) D R E A D D$ mouse (G) but not in the non-DREADD control $(\boldsymbol{J})$. $\boldsymbol{H}$, CNO treatment $\left(10.0 \mathrm{mg} / \mathrm{kg}\right.$ bw) increases the $\mathrm{CV}_{\mathrm{f}}$ compared to baseline in V2a-(G)DREADD mice $(p=0.030, n=6$ but not in non-DREADD control mice $(p=0.619, n=5 ; \boldsymbol{K})$. I, The average IS of the breathing frequency is increased in V2a- $\left(\mathrm{G}_{\mathrm{i}}\right)$ DREADD mice following CNO $(10.0 \mathrm{mg} / \mathrm{kg}$ bw; $p=0.031, n=6)$ but remains unchanged in non-DREADD control mice $(p=0.363, n=5 ; L)$. Gray dashed lines show individual animals. Solid black line shows the mean $\pm \mathrm{SE} ; * p<0.05$, paired $t$ test or Wilcoxon signed-rank test (Fig. 1/).

$n=8$; Fig. 3D). Consistent with WBP, the instantaneous bursting frequency of the diaphragm in $\mathrm{V} 2 \mathrm{a}-\left(\mathrm{G}_{\mathrm{i}}\right) \mathrm{DREADD}$ mice was significantly increased after CNO treatment $(188.0 \pm 11.4$ vehicle vs $237.553 \pm 20.2$ bursts $/ \mathrm{min}$ CNO, $p=0.04, n=4$; Fig. 3E). No change was observed after CNO treatment in non-DREADD controls $(193.7 \pm 8.6$ vehicle vs $187.7 \pm 14.6$ bursts $/ \mathrm{min}$ CNO, $p=0.733, n=$ 5; Fig. 3F). There is no difference in bursting frequency between genotypes following administration of vehicle only $(p=0.735)$. Thus, adult mice show a small increase in breathing frequency when V2a neurons are silenced rather than a dramatic decrease in frequency observed in neonatal mice.

We next assessed whether silencing V2a neurons impacts the regularity of breathing in adult $\mathrm{V} 2 \mathrm{a}-\left(\mathrm{G}_{\mathrm{i}}\right) \mathrm{DREADD}$ mice. To exclude potential effects caused by changes in ARM activity (see "Decreasing V2a neuron excitability increases ARM EMG activity"), we plotted the instantaneous frequency for 100 consecutive breaths during intervals in which ARMs are not active (interbout intervals). We observed a stable, consistent breathing frequency for each animal during vehicle and CNO treatment (Fig. $3 G, H)$. Breathing regularity is evident from Poincare plots that form a tight cluster in vehicle and CNO-treated V2a$\left(G_{i}\right)$ DREADD mice (Fig. $2 /, J$ ) as well as no effect of CNO treatment on the $\mathrm{CV}_{\mathrm{f}}(0.146 \pm 0.014$ vehicle vs $0.130 \pm$ 0.010 CNO, $p=0.492, n=9$; Fig. $3 K)$ or IS $(12.8 \pm 0.6 \%$ vehicle vs $11.6 \pm 0.8 \%$ CNO, $p=0.378, n=9$; Fig. $3 L$ ). These results demonstrate that, unlike in neonatal mice,
V2a neuron activity is not critical for maintaining a regular respiratory rhythm in adult mice.

\section{Decreasing V2a neuron excitability increases ARM EMG activity}

We next assessed the effect of decreasing V2a excitability on extradiaphragmatic respiratory muscle activity. Mice were instrumented with devices to non-invasively measure EMG from trapezius $(n=9)$ and either scalene $(n$ $=5$ ) or diaphragm $(n=4)$ muscles. V2a- $\left(G_{i}\right) D R E A D D$ mice were placed in a plethysmography chamber and muscle activity was measured after a vehicle injection and then after injecting CNO. The RMS of the EMG signal was used to identify bouts of increased muscle activity in mice at rest (Mantilla et al., 2011). There was no change in the percentage of time spent in a resting state before and after silencing V2a neurons $(47.3 \pm 5.2 \%$ vehicle vs 50.7 $\pm 5.8 \% \mathrm{CNO}, n=9, p=0.670$ ). Unexpectedly, we observed an increased incidence of bouts of trapezius and scalene activity after V2a neurons are inhibited (Fig. $4 A)$. The frequency of trapezius and scalene bouts is dependent on the dose of CNO, with the highest frequency in both muscles observed at a dose of $10.0 \mathrm{mg} / \mathrm{kg}$ bw CNO (Fig. 4B,C). A 9.3-fold increase in trapezius and 7.5-fold increase in scalene activity was observed following CNO treatment at this dose. Trapezius and scalene muscles were usually co-activated $(87 \pm 4 \%$ of scalene bouts coincided with trapezius bouts, $n=5$ ) following 
A -CNO B B +CNO

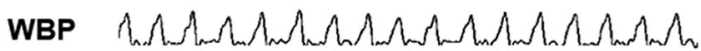
Dia. Jat

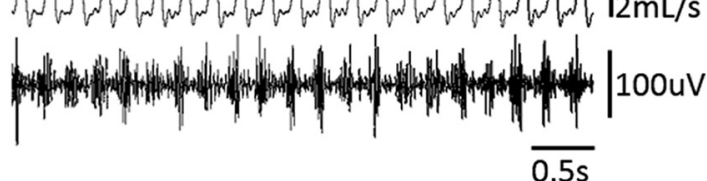

C

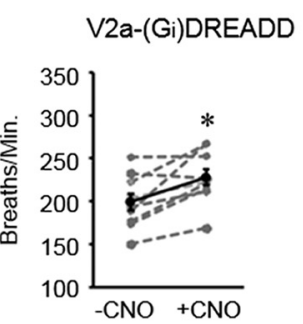

D

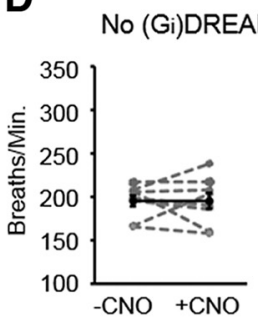

E

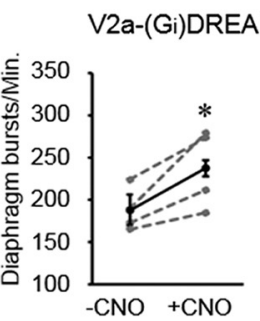

F

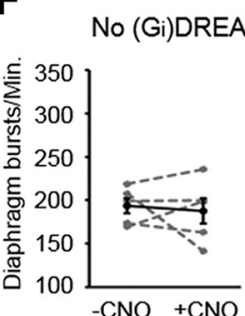

G

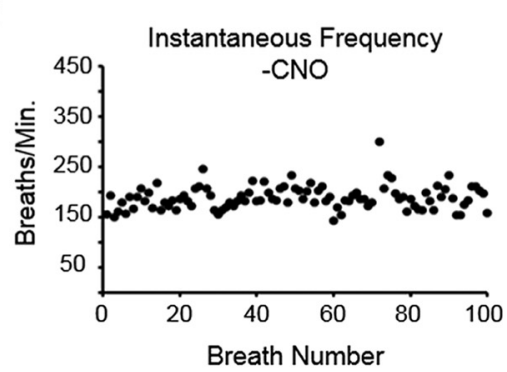

H

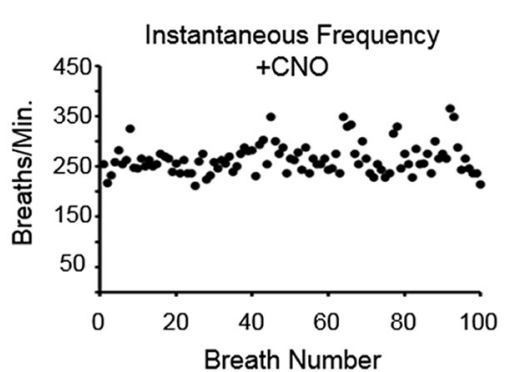

I

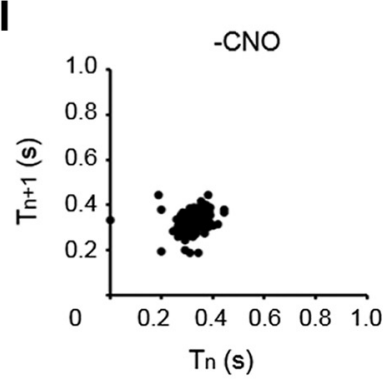

J

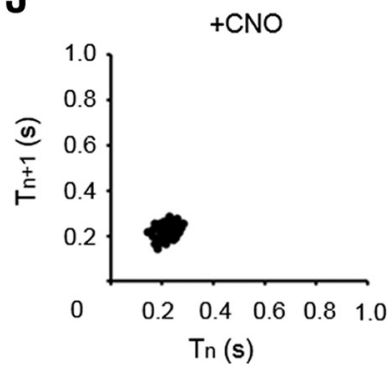

k

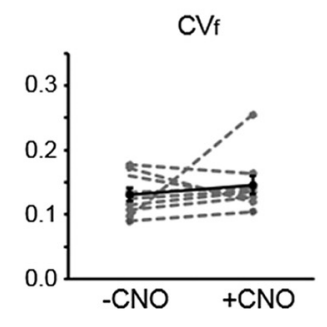

$\mathbf{L}$

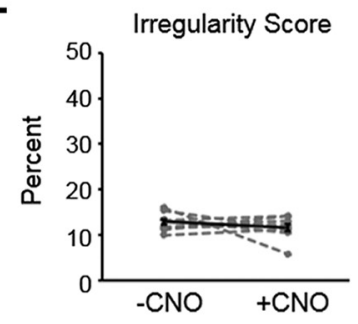

Figure 3. Decreasing the excitability of V2a neurons increases breathing frequency without causing irregular breathing in adult V2a- $\left(G_{i}\right)$ DREADD mice. $\boldsymbol{A}, \boldsymbol{B}$, Representative traces of WBP and diaphragm EMG following injections of vehicle $(\boldsymbol{A})$ and subsequently $10.0 \mathrm{mg} / \mathrm{kg}$ bw CNO $(\boldsymbol{B})$ into the same V2a- $\left(\mathrm{G}_{\mathrm{i}}\right)$ DREADD mouse on the same day. $\boldsymbol{C}, \boldsymbol{D}$, Instantaneous respiratory frequency was assessed in V2a- $\left(G_{i}\right)$ DREADD mice $(\mathbf{C})$ and non-DREADD $\left(\right.$ Chx $\left.10^{\mathrm{Cre} /+}\right)$ control mice $(\boldsymbol{D})$ by WBP after injection of vehicle (-CNO) and CNO. $\boldsymbol{E}, \boldsymbol{F}$, The instantaneous bursting frequency was calculated from the RMS ${ }^{\text {peak }}$ of the diaphragm EMG signal in V2a- $\left(G_{i}\right)$ DREADD mice $(\boldsymbol{E})$ and non-DREADD control mice $(\boldsymbol{F})$ after injection of vehicle $(-C N O)$ and $C N O$. $\boldsymbol{G}$, $\boldsymbol{H}$, Instantaneous respiratory frequency is plotted for 100 consecutive breaths in a V2a- $\left(G_{i}\right) D R E A D D$ mouse injected with vehicle (G) or $10.0 \mathrm{mg} / \mathrm{kg}$ bw CNO $(\boldsymbol{H})$ to illustrate the breath to breath consistency of respiratory frequency. $\boldsymbol{I}, \boldsymbol{J}$, Poincare maps generated by plotting the respiratory cycle period $\left(T_{n}\right)$ versus the subsequent respiratory cycle period $\left(T_{n+1}\right)$ from the same trials shown in $\boldsymbol{G}, \boldsymbol{H}$ show a consistent period following both vehicle $(\boldsymbol{I})$ and CNO $(\boldsymbol{J})$ treatments. $\boldsymbol{K}$, CNO treatment $(10.0 \mathrm{mg} / \mathrm{kg} \mathrm{bw}) \mathrm{does}$ not alter the $\mathrm{CV}_{\mathrm{f}}$ compared to vehicle (-CNO) treatment in V2a- $\left(\mathrm{G}_{\mathrm{i}}\right)$ DREADD mice $(p=0.492, n=9)$. $L$, The average breathing frequency IS of $\mathrm{V} 2 \mathrm{a}-\left(\mathrm{G}_{\mathrm{i}}\right)$ DREADD mice following vehicle and CNO $(10.0 \mathrm{mg} / \mathrm{kg} \mathrm{bw})$ is not significantly different $(p=0.378, n=$ 9 ). Gray dashed lines show individual animals. Solid black line shows the mean $\pm \mathrm{SE} ; * p<0.05$, paired $t$ test or Wilcoxon signed-rank test (Fig. $2 K$ ).

treatment with $10.0 \mathrm{mg} / \mathrm{kg}$ bw CNO, signifying that the bouts are a form of patterned activity. CNO does not increase trapezius or scalene activity in non-DREADD expressing control mice at any dose tested (Fig. 4D), demonstrating that the effects of $\mathrm{CNO}$ are the result of $\left(G_{i}\right)$ DREADD inhibition of V2a neurons. We observed a small but statistically significant difference in baseline trapezius ARM activity in V2a- $\left(G_{i}\right) D R E A D D$ mice not treated with CNO compared to non-DREADD controls at rest $\left[0.203 \pm 0.04\right.$ bouts $/ \mathrm{min}\left(\mathrm{G}_{\mathrm{i}}\right) \operatorname{DREADD}(n=9)$ vs $0.080 \pm 0.021$ bouts $/$ min control $(n=5), p=0.043$ ] However, a difference of 0.1 bouts/min is not biologically significant compared to the increase we see after CNO administration (1.46 bouts/min). Further, trapezius ARM activity in vehicle-treated $V 2 a\left(G_{i}\right) D R E A D D$ mice is comparable to what has previously been reported in 
A
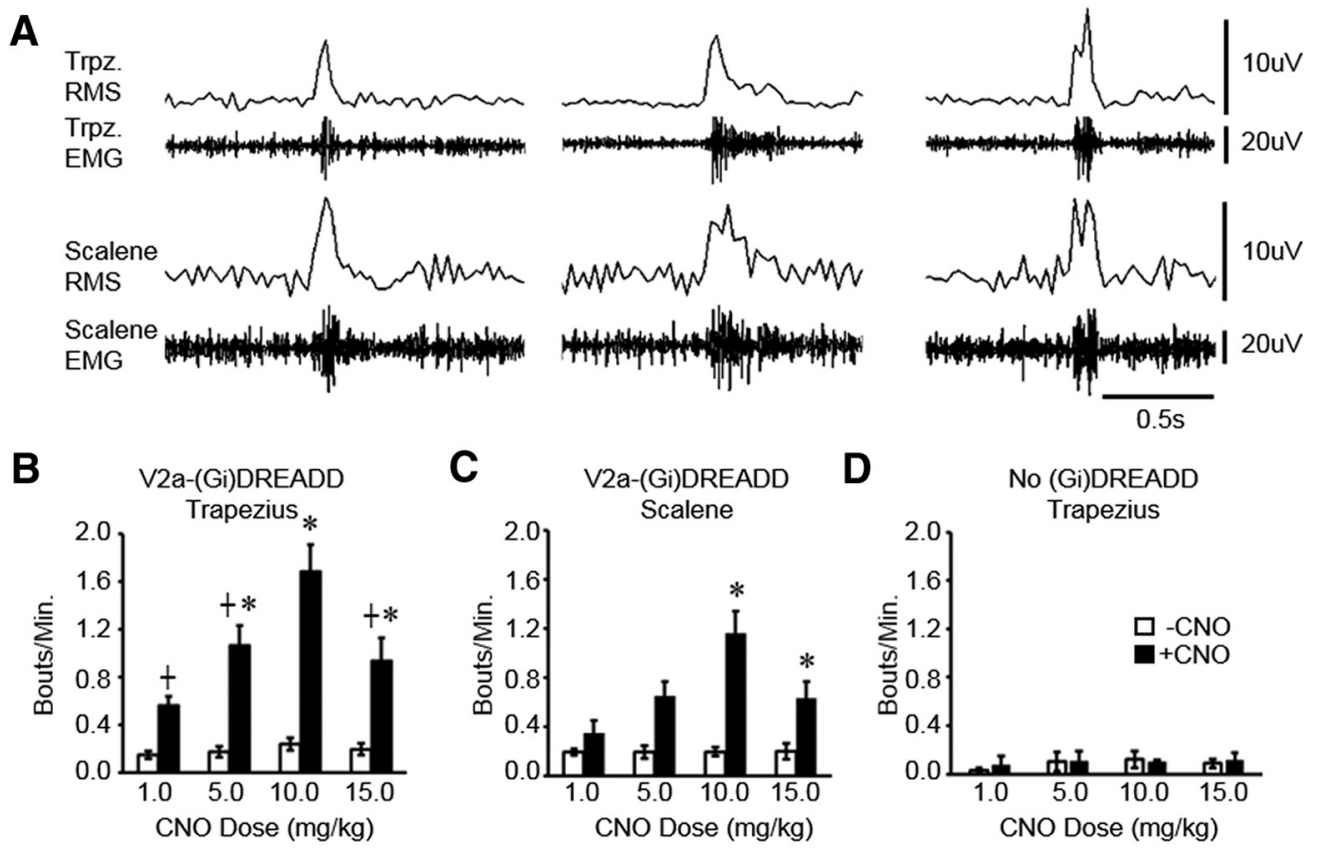

E

V2a-(Gi)DREADD

Trapezius Bout Frequency Over Time

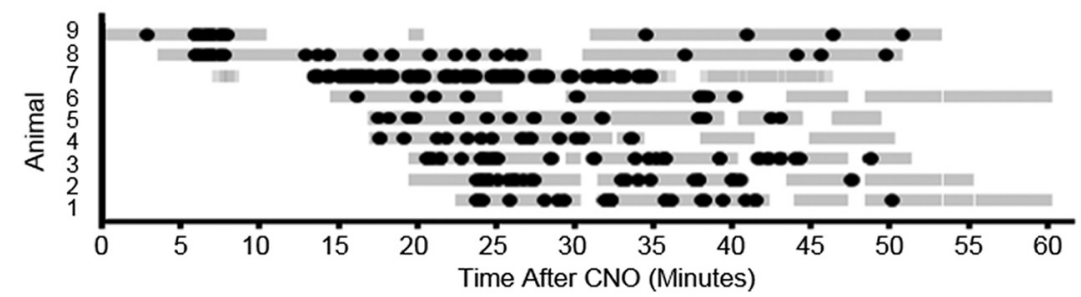

- Bout Resting

Figure 4. Decreasing the excitability of V2a neurons increases extradiaphragmatic respiratory muscle activity. A, Representative traces showing three different examples of bouts of trapezius and scalene EMG activity (recorded simultaneously) following injection of $10.0 \mathrm{mg} / \mathrm{kg}$ bw CNO into a V2a-(G) DREADD mouse. The RMS of the EMG signal is shown above the EMG trace for each muscle. The frequency of trapezius $(B ; n=9)$ and scalene $(\boldsymbol{C} ; n=5)$ bouts was measured before CNO treatment (white bars) as well as following 1.0-15.0 mg/kg bw CNO (black bars) in V2a-(G) DREADD mice. Experiments using different doses of CNO were performed on separate days within the same animals. $\boldsymbol{D}$, CNO treatment (1.0-15.0 mg/kg bw) does not increase trapezius bout frequency in non-DREADD control $\left(\mathrm{Ch} \times 10^{\mathrm{Cre} /+}\right)$ mice lacking the $\mathrm{V} 2 \mathrm{a}-\left(\mathrm{G}_{\mathrm{i}}\right) \mathrm{DREADD}$ receptor $(n=5)$. $\boldsymbol{E}$, The time point when each ARM bout occurred for the trapezius $(n=9)$ is plotted for each mouse (black dot) across the hour-long EMG recording following CNO treatment. Gray highlighted regions represent time periods each mouse spent in the resting state when ARM bout frequency could be analyzed; $*$, treatment group is significantly different from vehicle control ( $p<0.05$, one-way repeated measures ANOVA $p<0.05$ ); + , group is different from $10.0 \mathrm{mg} / \mathrm{kg}$ bw CNO ( $p<0.05$, one-way repeated measures ANOVA). Gray dashed lines show individual animals. Solid black line shows the mean \pm SE.

wild-type mice $(0.176 \pm 0.038$ bouts/min; Romer et al., 2017), indicating that this group of non-DREADD control mice had a particularly low level of baseline ARM activity. Finally, we plotted the occurrence of each trapezius bout over the hour-long recording period for each animal to characterize the timing of ARM activation, with time spent in the resting state indicated with gray bars (Fig. 4E). Results show that ARM bouts can occur as soon as 5 min following CNO treatment (accounting for the 2-min reacclimation to the chamber following CNO injection) and substantially declines within the last $15 \mathrm{~min}$ of the hour-long recording. In summary, inhibition of $\mathrm{V} 2 \mathrm{a}$ neuron activity causes an increase in the incidence of trapezius and scalene muscle activity in mice at rest.

\section{Diaphragm EMG peak amplitude is not altered when V2a excitability is decreased}

To address the possibility that increased ARM activity resulting from silencing $\mathrm{V} 2 \mathrm{a}$ neurons is a compensatory response to impaired diaphragm function, we analyzed the diaphragm EMG signal in V2a- $\left(G_{i}\right) D R E A D D$ mice and controls implanted with leads in the diaphragm and trapezius muscles (Fig. 5A). The peak amplitude of the RMS of the EMG signal (RMS ${ }^{\text {peak }}$ ) was used to measure the amplitude of each burst of diaphragm activity (each breath) as well as trapezius activity during bouts and interbout intervals. The RMS ${ }^{\text {peak }}$ amplitude was normalized to the amplitude during near maximal ventilatory behavior (sighs) for each muscle to reduce intra-animal variability (Mantilla et al., 2011). The trapezius RMS ${ }^{\text {peak }}$ 

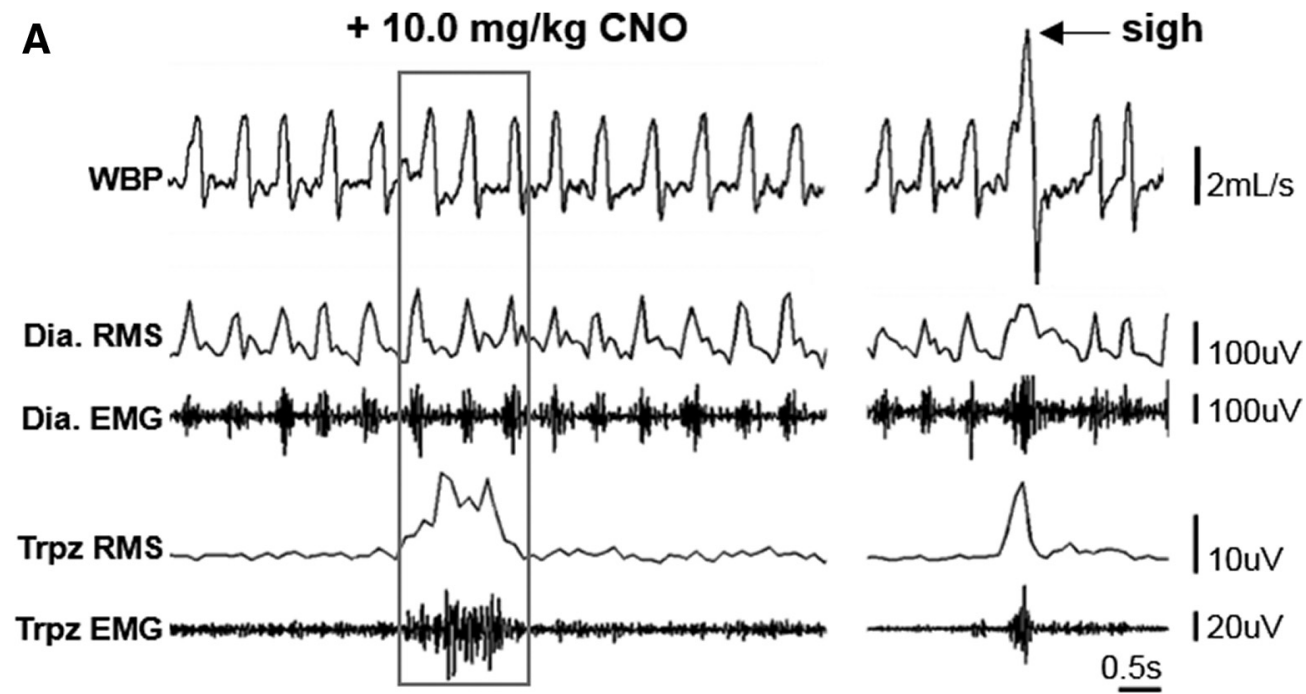

B

\section{Eupnea}

Nasal Occlusion
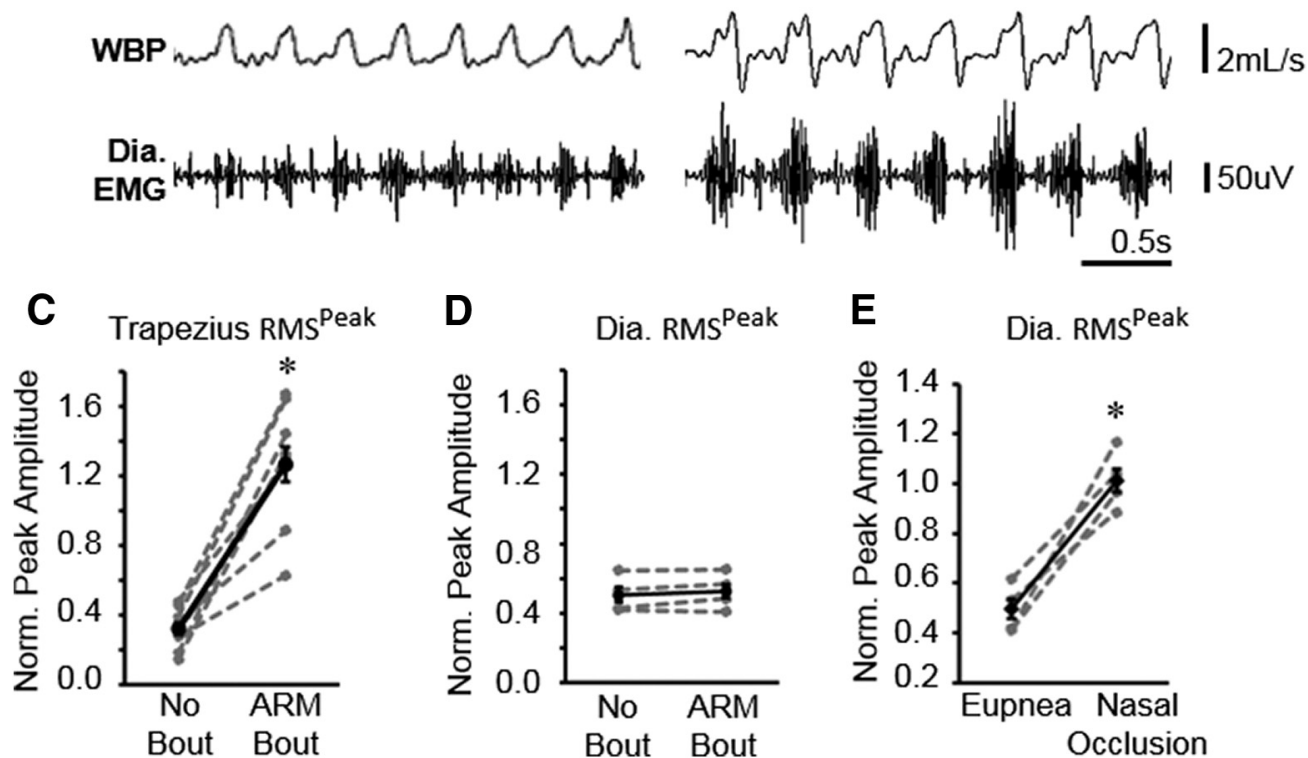

Figure 5. Diaphragm EMG peak amplitude does not change during ARM bouts. $\boldsymbol{A}$, Representative traces showing WBP as well as diaphragm and trapezius EMG signals recorded simultaneously from a V2a-(Gi)DREADD mouse. The RMS of the EMG signal is shown above the EMG trace for each muscle. Left, The gray box indicates a bout of trapezius activity in a CNO-treated mouse. Right, WBP, EMG, and RMS signals from the same mouse during a sigh (near maximal ventilation, arrow). $\boldsymbol{B}$, Representative trace showing WBP and diaphragm EMG during eupnea and during nasal occlusion. $\boldsymbol{C}, \boldsymbol{D}$, Diaphragm activity is not increased during bouts of increased trapezius activity. $\boldsymbol{C}$, Trapezius RMS ${ }^{\text {peak }}$ values were normalized to trapezius RMS ${ }^{\text {peak }}$ values during sighs to calculate the average normalized peak amplitude of trapezius activity for each animal ( $n=9$ animals) during bouts of trapezius activity (ARM bout) and during interbout intervals (no bout). $\boldsymbol{D}$, Diaphragm RMS ${ }^{\text {peak }}$ during bouts of trapezius activity and during interbout intervals, normalized to diaphragm $\mathrm{RMS}^{\text {peak }}$ during sighs for each animal $(n=4)$. $\boldsymbol{E}$, Diaphragm $\mathrm{RMS}^{\text {peak }}$ is increased during nasal occlusion $(n=4, * p<$ 0.05 , paired $t$ test). Gray dashed lines represent individual animals. Solid black lines show the mean \pm SE for all animals.

is not significantly different between animals implanted in the trapezius and diaphragm $(n=4)$ compared to trapezius and scalene ( $n=5 ; t$ test $p=0.938$ ), so these two groups were pooled for analysis of trapezius $\mathrm{RMS}^{\text {peak }}$. We observe a 4.2-fold increase in trapezius $\mathrm{RMS}^{\text {peak }}$ during a bout compared to interbout intervals (Fig. 5C). In contrast, we observe no significant change in diaphragm RMS ${ }^{\text {peak }}$ during bouts of trapezius activity compared to interbout intervals (Fig. 5D) and no change in diaphragm $\mathrm{RMS}^{\text {peak }}$ during interbout intervals following CNO injection compared to vehicle only $(0.51 \pm 0.05$ vehicle vs $0.52 \pm 0.05 \mathrm{CNO}, n=4$, paired $t$ test $p=0.889$ ). However, we verified that our devices are capable of measuring changes in diaphragm $\mathrm{RMS}^{\text {peak }}$ during different behaviors by performing nasal occlusion for $4 \mathrm{~min}$ on the same V2a- $\left(G_{i}\right) D R E A D D$ mice (Fig. $5 B$ ). Nasal occlusion is known to increase ventilatory drive and increase diaphragm RMS $^{\text {peak }}$ (Mantilla et al., 2011). We measured a 2.1-fold 
A - CNO

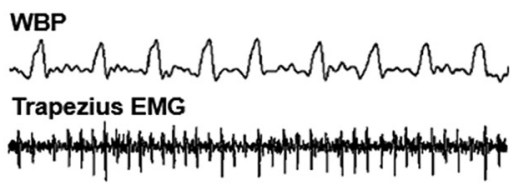

B

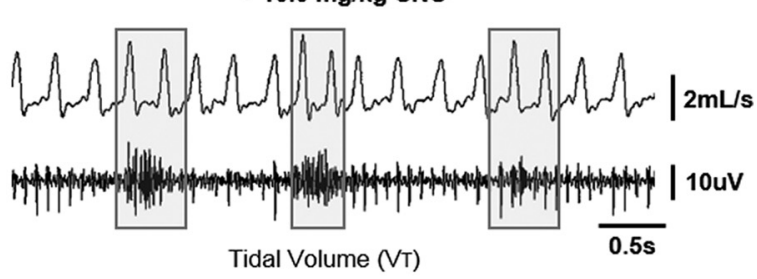

C
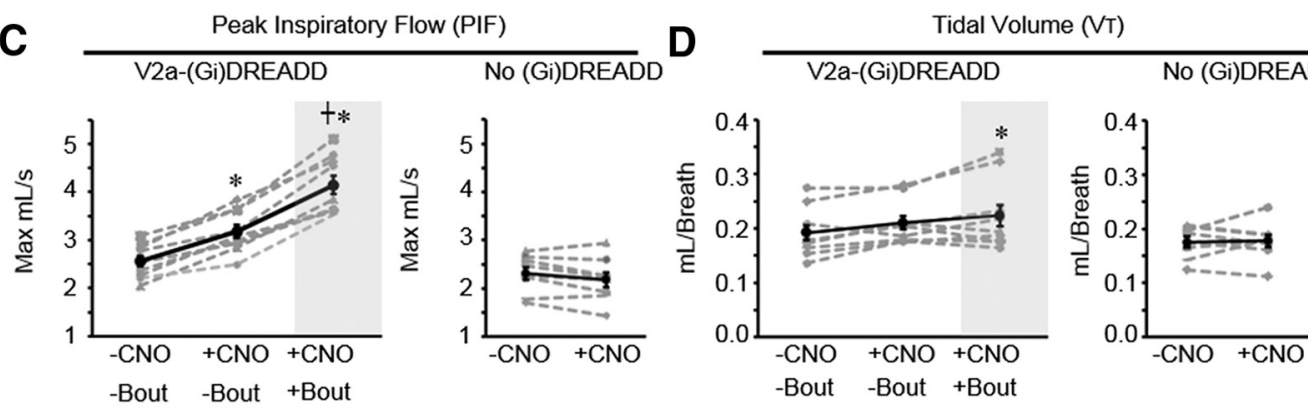

E

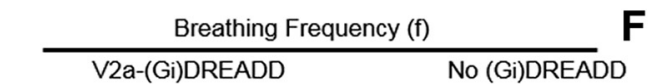

\section{$F$}
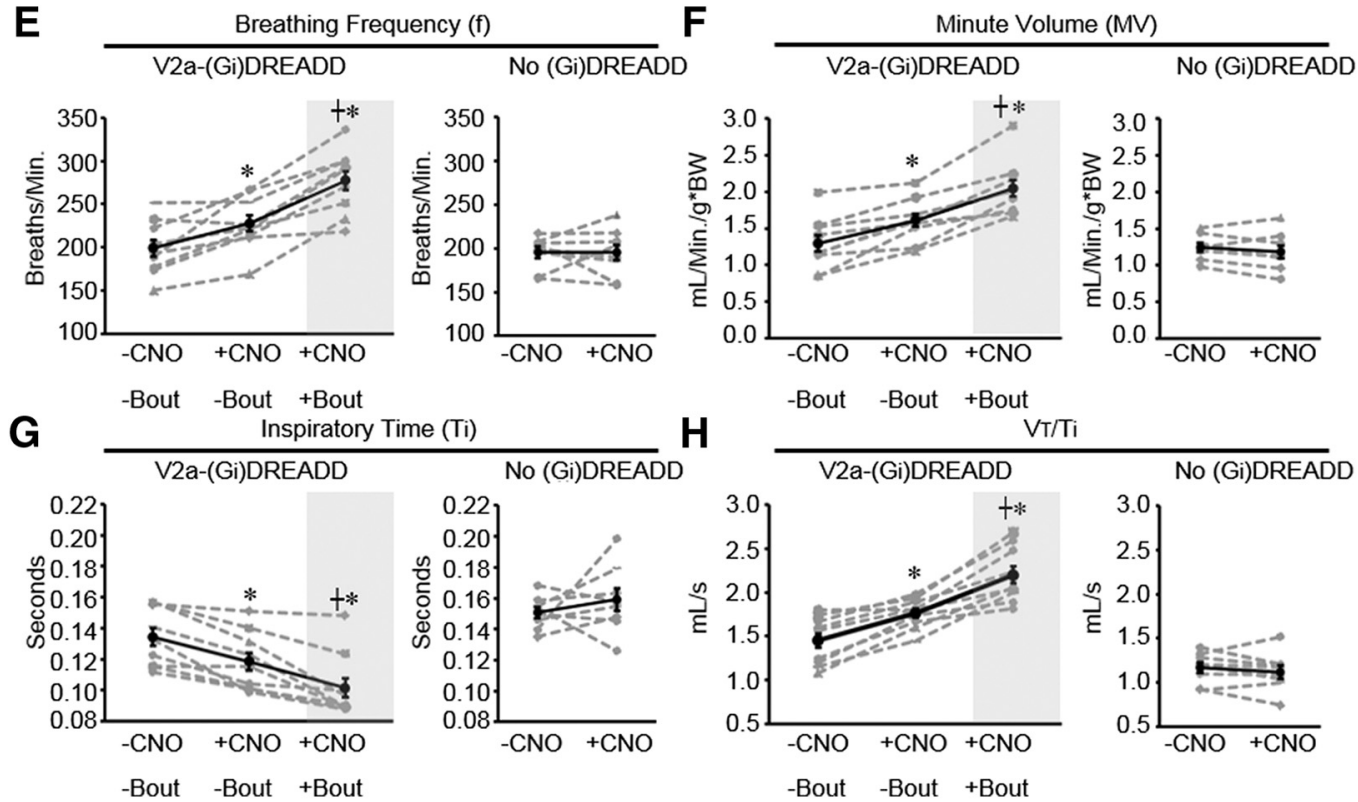

Figure 6. Ventilation is increased during bouts of ARM activity. $\boldsymbol{A}$, Representative trace showing WBP and trapezius EMG following injection of vehicle. $\boldsymbol{B}$, Representative trace showing WBP and trapezius EMG after injection of $10.0 \mathrm{mg} / \mathrm{kg}$ bw CNO. Gray boxes outline trapezius bouts and corresponding changes in WBP. PIF $(\boldsymbol{C}), \mathrm{V}_{\mathrm{T}}(\boldsymbol{D})$, breathing frequency (BPM; $\left.\boldsymbol{E}\right), \mathrm{MV}(\boldsymbol{F}), \mathrm{T}_{\mathrm{i}}(\boldsymbol{G})$, and $\mathrm{V}_{\mathrm{T}} / \mathrm{T}_{\mathrm{i}}$ $(\boldsymbol{H})$ were measured within the same V2a- $\left(\mathrm{G}_{\mathrm{j}}\right) \mathrm{DREADD}$ mice $(n=9)$ and non-DREADD control mice $(n=8)$ during interbout intervals in the absence of CNO, during interbout intervals with $10.0 \mathrm{mg} / \mathrm{kg}$ bw CNO, and during trapezius bouts with $10.0 \mathrm{mg} / \mathrm{kg}$ bw CNO. The low frequency of ARM activity in non-DREADD controls precluded measurement of WBP during ARM bouts; *, group is different from -CNO/-bout (vehicle control);,$++\mathrm{CNO}$ / bout is different from $+\mathrm{CNO} /$-bout $(p<0.05$, one-way repeated measures ANOVA with all comparisons Holm-Sidak post hoc test for V2a- $\left(\mathrm{G}_{i}\right)$ DREADD mice or paired $t$ test for non-DREADD controls). Gray dashed lines show individual animals. Solid black line shows the mean \pm SE.

increase in diaphragm RMS ${ }^{\text {peak }}$ following nasal occlusion compared to eupnea (Fig. 5E), consistent with previously published literature. Thus, despite our ability to detect increases in the peak amplitude of diaphragm muscle activity during sighs and nasal occlusion, we did not observe a change in diaphragm peak amplitude in V2a- $\left(G_{i}\right) D R E A D D$ mice following $\mathrm{CNO}$ treatment.

\section{Decreasing V2a neuron excitability increases ventilation}

To assess the impact on ventilation of decreasing $\mathrm{V} 2 \mathrm{a}$ neuron excitability, we analyzed WBP to compare venti- lation following $\mathrm{CNO}$ injection to vehicle control injections. We first focused our analysis on interbout intervals to exclude potential effects on ventilation caused by increased ARM recruitment. We observed a $24.6 \%$ increase in PIF, $28.6 \%$ increase in MV, and $15.3 \%$ increase in breathing frequency (f) in V2a-(G)DREADD mice after silencing $\mathrm{V} 2 \mathrm{2}$ neurons, but no change was observed in $\mathrm{V}_{\mathrm{T}}$ (Fig. 6A-F). In addition, there was no significant difference in sigh frequency following $\mathrm{CNO}$ injection compared to vehicle $(0.54 \pm 0.14$ vehicle vs $0.54 \pm 0.05 \mathrm{CNO} ; p=$ $0.812)$. We assessed ventilatory drive by measuring $V_{T} / T_{i}$ (Morgan et al., 2014) and found that it is increased follow- 
ing CNO treatment, primarily driven by a decrease in $T_{i}$ (Fig. 6G,H). Importantly, the effects of CNO on ventilation are caused by altering $G_{i}$ protein signaling in V2a neurons because we observed no CNO-dependent changes in PIF, $\mathrm{V}_{\mathrm{T}}, \mathrm{MV}$, or $\mathrm{f}$ in non-DREADD control mice (Fig. 6C-F). We also investigated any potential effects of $\left(G_{i}\right)$ DREADD expression alone on breathing by comparing ventilation parameters in V2a- $\left(G_{i}\right) D R E A D D$ and non-DREADD controls following vehicle injection. We did not find a statistically significant difference in PIF (V2a- $\left(G_{i}\right)$ DREADD: $2.562 \pm 0.120$ vs non-DREADD $2.306 \pm 0.139 ; p=$ $0.182), \mathrm{V}_{\mathrm{T}}(0.192 \pm 0.014$ vs $0.176 \pm 0.010 ; p=0.716)$, $\mathrm{MV}(1.24 \pm 0.06$ vs $1.29 \pm 0.10 ; p=0.728), \mathrm{f}(199.2 \pm 9.4$ vs $195.6 \pm 6.3 ; p=0.066)$, or Ti $(0.134 \pm 0.006$ vs 0.151 $\pm 0.004 ; p=0.136$ ). Our results are the first to demonstrate that inhibiting V2a neurons in adult animals impacts ventilation, even during the intervals between bouts of ARM activity.

We further investigated the impact of increased ARM activity on breathing by comparing ventilation during bouts of trapezius activity to ventilation during interbout intervals in V2a- $\left(G_{i}\right) D R E A D D$ mice implanted with leads in the diaphragm and trapezius $(n=4)$. Significant increases are observed in PIF (30.6\%), MV (28.0\%), and f (22.2\%) during ARM bouts compared to interbout intervals in V2a- $\left(G_{i}\right)$ DREADD mice treated with CNO (Fig. 6C,E,F). There is a modest $(15.6 \pm 2.9 \%)$ increase in $V_{T}$ during ARM bouts that is statistically significant compared to $V_{T}$ during interbout intervals in the absence of CNO (Fig. 6D). $\mathrm{V}_{\mathrm{T}} / \mathrm{T}_{\mathrm{i}}$ is increased during ARM bouts, primarily due to a significant decrease in $T_{i}$ (Fig. 6G,H). The decrease in $T_{i}$ and increase in $f$ during bouts is consistent with a decrease in diaphragm EMG burst duration (64 \pm 3 ms bout, $97 \pm 3 \mathrm{~ms}$ no bout; $p=0.003)$ and increase in $\mathrm{f}(298 \pm 10$ bursts/min bout, $238 \pm 18$ no bout; $p=0.012$ ) following CNO injections observed in V2a-(Gi)DREADD mice. We did not attempt to quantify ventilatory parameters during trapezius activity in non-DREADD expressing mice or V2a-(Gi)DREADD mice during vehicle injections due to the rarity of ARM bouts in control mice. These data show that the ARM activity resulting from inhibition of V2a neurons is associated with a further increase in ventilation over that observed during interbout intervals.

To determine whether ARM activity might be triggered by a change in ventilation, we compared MV during the four breaths immediately preceding each bout of ARM activity to the average MV during interbout intervals and found no significant difference $(1.52 \pm 0.06$ vs $1.61 \pm$ $0.09 \mathrm{ml} / \mathrm{min}$ per $\mathrm{g} / \mathrm{bw} ; p=0.392$ ). We also detected no significant differences in PIF (3.22 \pm 0.11 vs $3.18 \pm 0.14$ $\max \mathrm{ml} / \mathrm{s} ; p=0.823)$, VT $(0.19 \pm 0.01$ vs $0.21 \pm 0.01$ $\mathrm{ml} / \mathrm{breath} ; p=0.282)$, or $\mathrm{f}(227.1 \pm 9.8$ vs $227.7 \pm 9.7$ breaths $/ \mathrm{min} ; p=0.922$ ) during breaths immediately preceding a bout compared to interbout intervals. However, we did observe a small but significant decrease in $T_{i}$ immediately preceding a bout $(0.11 \pm 0.01$ vs $0.19 \pm 0.01$ $\mathrm{s} ; p=0.030$ ). Thus, the majority of ventilation parameters are not significantly altered immediately before the onset of ARM bouts.

\section{Increasing and decreasing the excitability of V2a neurons differentially affects motor functions}

It has previously been shown that increasing the excitability of V2a neurons with CNO in V2a- $\left(\mathrm{G}_{\mathrm{q}}\right)$ DREADD mice activates ARMs (Romer et al., 2017). Since increasing and decreasing the excitability of V2a neurons both increase the incidence of ARM bouts, we examined the effects of altering the excitability of V2a neurons on other motor activities. Wild-type mice can fully splay their hindlimbs when lifted by the tail (Fig. 7A), whereas mice lacking V2a neurons do not extend their hindlimbs $(n=3$; Fig. $7 B)$. Before CNO treatment, V2a- $\left(G_{i}\right)$ DREADD mice fully extend their hindlimbs when suspended by the tail, like wild-type mice. However, following CNO treatment (10 $\mathrm{mg} / \mathrm{kg}$ bw), V2a- $\left(G_{i}\right)$ DREADD mice $(n=3)$ lose this hindlimb extension reflex and their limbs hang in a relaxed manner (Fig. $7 C)$. V2a- $\left(G_{q}\right)$ DREADD mice $(n=3)$ show normal hindlimb extension before and after treatment with CNO (1.0 mg/kg bw; Fig. 7D). The selected doses of CNO were those that elicited the greatest increase in ARM activity for each mouse line. Thus, increasing and decreasing the excitability of V2a neurons has distinct effects on a hindlimb extension reflex.

Next, we examined the effects of increasing and decreasing the excitability of V2a neurons on diaphragm activity by performing terminal diaphragm EMG recordings under isoflurane anesthesia. Similar to what is observed in conscious V2a- $\left(\mathrm{G}_{\mathrm{i}}\right)$ DREADD mice instrumented with telemetry transmitters, silencing V2a neurons does not alter the diaphragm EMG peak amplitude $(0.61 \pm 0.07$ vehicle vs $0.52 \pm 0.03 \mathrm{CNO}, n=3$, paired $t$ test, $p=$ 0.376 ) or regularity of diaphragm bursting in anesthetized mice $\left(\mathrm{CV}_{\mathrm{f}}: 0.04 \pm 0.004\right.$ vehicle vs $0.04 \pm 0.003 \mathrm{CNO}, n$ $=3$, paired $t$ test, $p=0.903$; IS: $3.94 \pm 0.27$ vehicle vs $3.97 \pm 0.27 \mathrm{CNO}, n=3$, paired $t$ test, $p=0.935$; Fig. $7 E, F)$. We then used the same protocol to assess diaphragm EMG activity after increasing the excitability of V2a neurons in V2a- $\left(G_{q}\right)$ DREADD mice. CNO does not alter the normalized diaphragm EMG peak amplitude in anesthetized mice $(0.46 \pm 0.04$ pre CNO vs $0.44 \pm 0.03$ post CNO, $n=5$, paired $t$ test, $p=0.984$; Fig. $7 G-l)$. However, we observed additional activity during the expiratory phase of the respiratory cycle in 5 out of $5 \mathrm{~V} 2 \mathrm{a}-$ $\left(G_{\mathrm{q}}\right)$ DREADD mice (Fig. 7I). Expiratory diaphragm activity is observed intermittently during $44 \pm 8 \%$ of the total recording time following CNO treatment with an average duration of $308 \pm 112 \mathrm{~s}$. In contrast, activity during the expiratory phase is not observed in $\mathrm{V} 2 \mathrm{a}-\left(\mathrm{G}_{\mathrm{i}}\right) \mathrm{DREADD}$ mice $(n=3$; Fig. 7F). These results demonstrate that although increasing and decreasing the excitability of V2a neurons has similar effects on ARM activity, the two manipulations have distinct effects on diaphragm activity during the expiratory phase of respiration.

\section{Discussion}

In this study, we tested the role of brainstem and spinal cord V2a neurons in respiratory rhythm generation and pattern formation by acutely silencing $\mathrm{V} 2 \mathrm{a}$ neurons in conscious neonatal or adult mice using an inhibitory DREADD while measuring respiratory muscle activity and ven- 

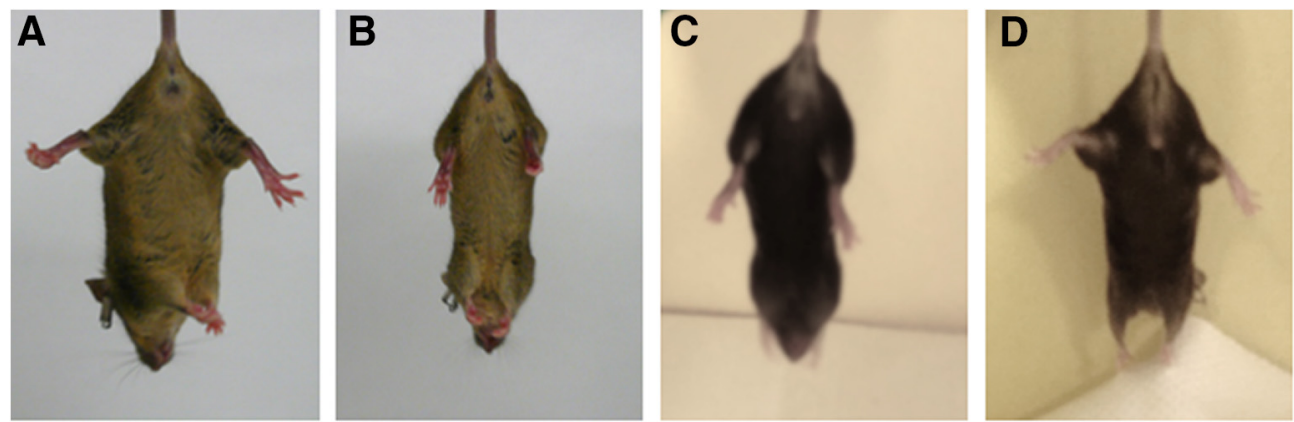

\section{V2a-(Gi)DREADD}
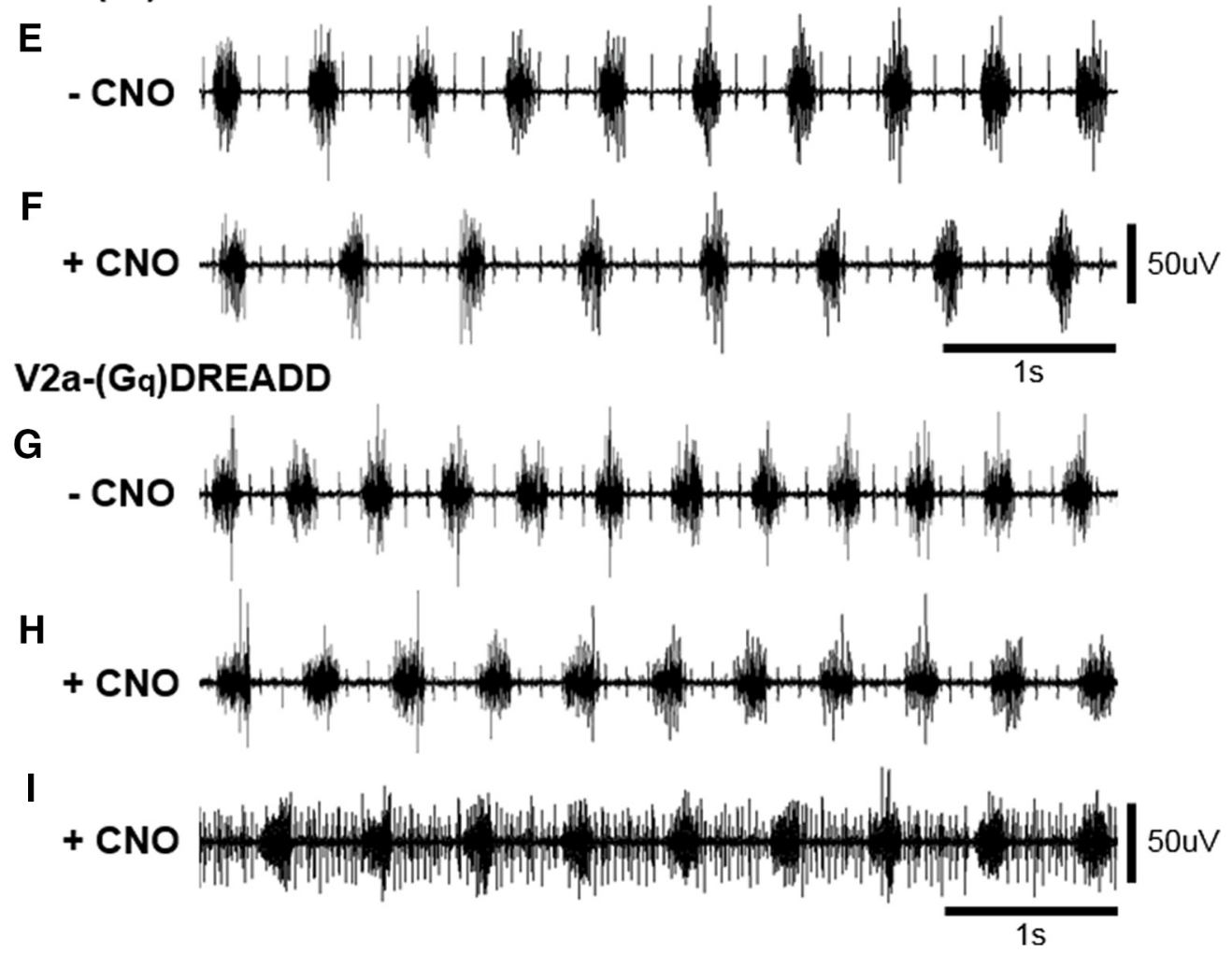

Figure 7. Increasing and decreasing the excitability of V2a neurons differentially affects motor functions. $\boldsymbol{A}-\boldsymbol{D}$, Mice were suspended by the tail to assess hindlimb extension. $\boldsymbol{A}$, Wild-type mice extend their hindlimbs. $\boldsymbol{B}$, Chx10::DTA mice (in which V2a neuron were ablated during development) do not splay their hindlimbs. C, V2a- $\left(\mathrm{G}_{\mathrm{i}}\right) \mathrm{DREADD}$ mice treated with $10 \mathrm{mg} / \mathrm{kg}$ bw $\mathrm{CNO}$ do not splay their hindlimbs. $\boldsymbol{D}, \mathrm{V} 2 \mathrm{a}-\left(\mathrm{G}_{\mathrm{q}}\right) \mathrm{DREADD}$ mice treated with $1.0 \mathrm{mg} / \mathrm{kg}$ bw CNO splay their hindlimbs. $\boldsymbol{E}-\boldsymbol{I}$, Diaphragm EMG was recorded under isoflurane anesthesia in V2a- $\left(G_{i}\right) D R E A D D$ and V2a- $\left(G_{q}\right) D R E A D D$ mice. Normal diaphragm bursting activity is observed in V2a$\left(\mathrm{G}_{\mathrm{i}}\right)$ DREADD mice before $(\boldsymbol{E})$ and after $(\boldsymbol{F})$ silencing V2a neurons with $10 \mathrm{mg} / \mathrm{kg}$ bw CNO, as well as in V2a-(G $\left.\mathrm{G}_{\mathrm{q}}\right)$ DREADD mice before CNO treatment $(\boldsymbol{G})$. V2a- $\left(G_{\mathrm{q}}\right)$ DREADD mice treated with $1.0 \mathrm{mg} / \mathrm{kg}$ bw CNO alternate between a normal diaphragm bursting pattern $(\boldsymbol{H})$ and a pattern that also includes diaphragm activity during the expiratory phase (I).

tilation. We show that $\mathrm{V} 2 \mathrm{a}$ neural activity is required to maintain the frequency and regularity of breathing in neonatal mice. However, V2a neuron activity is not required to maintain respiratory rhythm regularity in adult mice. In addition, we show that decreasing the excitability of V2a neurons results in activation of extradiaphragmatic respiratory muscles and increased ventilation, with little effect on diaphragm activity. Thus, during the neonatal period V2a neuron function is critical for respiratory rhythm generation, whereas in adults V2a neurons play an important role in patterning the activity of extradiaphragmatic respiratory muscles.
Our study also suggests that inhibiting V2a neuron activity could be a safe, effective method to increase ARM activity and ventilation without impairing diaphragm function in adult patients with neuromuscular disease or spinal cord injury.

This study is the first to demonstrate that acutely silencing V2a neurons in neonatal mice causes slow and irregular breathing. A limitation of a prior study in which V2a neurons were ablated during development (Crone et al., 2012) is that it was not possible to distinguish between the acute functions of V2a neurons in neonatal mice versus potential developmental defects that might 
have resulted from the loss of V2a neurons in the embryo. Importantly, CNO does not alter the frequency or regularity of breathing in non-DREADD expressing mice, demonstrating that our results are not due to off-target effects of $\mathrm{CNO}$ on other cell types. Further, we observe no difference in breathing frequency or pattern in V2a$\left(G_{i}\right)$ DREADD mice and non-DREADD control mice before CNO treatment, indicating that DREADD expression alone does not appear to impair the development or function of V2a neurons. Within the medulla, V2a neurons are located in the medial reticular formation and are distinct from several other classes of neurons known to influence respiration, including the $\mathrm{Dbx} 1^{+} \mathrm{V} 0$ neurons of the ventral respiratory group, Phox $2 \mathrm{~b}^{+}$and Atoh $1^{+}$neurons of retrotrapezoid nucleus/parafacial respiratory group, $L m \times 1 b^{+}$ and Pet $1^{+}$catecholaminergic and serotonergic neurons, and $\mathrm{Pax} 2^{+}, \mathrm{Lbx}_{1}{ }^{+}$, and FoxP2 ${ }^{+}$neurons of the brainstem (Gray, 2013; Dick et al., 2018). Our study is consistent with prior studies indicating that V2a neurons in the medial reticular formation of the brainstem provide excitatory drive to neurons in the pre-Bötzinger complex (likely V0 neurons) required for normal respiratory rhythm generation in neonatal mice (Crone et al., 2012).

By performing acute silencing experiments in adult mice, we show that V2a neuron activity is not required in mature animals for regular breathing rhythm. In fact, instead of slowing respiration, we observe a small increase in frequency when V2a neurons are silenced in the adult. Prior studies in which V2a neurons were ablated could not distinguish whether the recovery of a normal breathing rhythm after the first week of birth was because V2a neurons are no longer needed at older ages or the result of compensatory changes caused by ablation. Our results demonstrate that the role of V2a neurons in modulating respiratory rhythm changes during normal postnatal development. It is unlikely that the lack of slow and irregular breathing after silencing V2a neurons in adult mice is due to downregulation of the $\left(G_{i}\right) D R E A D D$ receptor in V2a neurons during maturation since there is no difference in the percentage of V2a neurons that express the $\left(G_{i}\right) D R E-$ ADD receptor between neonatal and adult mice in both the brainstem and spinal cord. It is also unlikely that this difference is the result of dramatic changes in connectivity between V2a neurons and brainstem respiratory centers since increasing V2a neuron excitability can increase respiratory frequency in adult mice (Romer et al., 2017). Moreover, V2a neurons appear to project throughout the ventral respiratory column in adult mice (Romer et al., 2017; our unpublished observations). Many changes occur in the neural control of respiration during the perinatal period, including changes in chemosensation (Guyenet and Bayliss, 2015), neuromodulator signaling (Gray et al., 1999; Hilaire and Duron, 1999; Hilaire et al., 2004; Doi and Ramirez, 2008; Wong-Riley and Liu, 2008), inhibitory neurotransmission (Hübner et al., 2001; Okabe et al., 2015; Dubois et al., 2018), afferent regulation (Hilaire and Duron, 1999; Dutschmann et al., 2004), pontine-medullary interactions (Oku et al., 2007; Dutschmann and Dick, 2012; Del Negro et al., 2018), as well as morphology and properties of respiratory network neurons (Denavit-Saubié et al.,
1994; Di Pasquale et al., 1996; Richter and Smith, 2014). Thus, the loss of excitatory drive provided by V2a neurons may be largely mitigated by other sources of drive in the adult that are not present or sufficient to restore breathing rhythm in newborn mice. Alternatively, drive from V2a neurons may only be required under specific conditions or behaviors in adult mice that were not tested in the present study (e.g., running).

Although we cannot rule out the possibility that the small population of V2a neurons that apparently lack DREADD expression are sufficient to maintain the frequency and regularity of breathing in adult mice, this seems unlikely given our results that this population is insufficient to maintain normal breathing in neonatal mice. Despite the fact that we are unable to detect DREADD expression in a significant fraction of medullary V2a neurons (35\% of $\mathrm{Ch} \times 10^{+}$cells), we observe a strikingly similar severity of phenotype in neonatal V2a- $\left(G_{i}\right) D R E A D D$ mice treated with $\mathrm{CNO}$ as observed in Chx10::DTA mice in which $>98 \%$ of V2a neurons were ablated during development (Crone et al., 2012). We do not know whether this is because silencing a majority of V2a neurons is sufficient to impair breathing or whether we are underestimating the fraction of V2a neurons expressing $\left(G_{i}\right) D R E A D D$ due to limitations in the sensitivity of our HA antibody. Further, we observe specific motor deficits (including failure of hindlimbs to splay when mice are suspended by the tail and increased ankle extension when walking) in adult V2a-(Gi)DREADD mice treated with CNO that are consistent with loss of V2a neuron function because they are also observed in mice in which V2a neurons are ablated (our unpublished observations).

Our study has also revealed an unexpected role for V2a neurons in constraining extradiaphragmatic respiratory muscle activity at rest. We observed coordinated activation of scalene and trapezius muscles at rest when V2a neurons were silenced. Interestingly, these results mimic the effects of activating V2a neurons at rest in healthy V2a- $\left(G_{\mathrm{q}}\right)$ DREADD mice with the excitatory $\left(\mathrm{G}_{\mathrm{q}}\right)$ DREADD receptor (Romer et al., 2017). It is unlikely that one DREADD strategy (activating or silencing) is failing because we observe different effects of CNO on the diaphragm in V2a$\left(\mathrm{G}_{i}\right) D R E A D D$ mice versus $V 2 a-\left(G_{q}\right) D R E A D D$ mice. Specifically, activating V2a neurons causes activity during the expiratory phase of the respiratory cycle, whereas silencing V2a neurons does not. We also observe that V2a-(G)DREADD mice, but not V2a- $\left(G_{c}\right) D R E A D D$ mice, fail to splay their legs when suspended by the tail after CNO treatment, a phenotype observed after V2a neurons have been ablated. Together, these results demonstrate that although silencing and activating V2a neurons both increase ARM activity in healthy mice, each manipulation has distinct effects on diaphragm activity and hindlimb reflexes.

Alternatively, it is possible that decreasing V2a neuron excitability impairs diaphragm function and thereby causes a compensatory increase in ARM activity. However, this mechanism is not consistent with our results as diaphragm $R M S^{\text {peak }}$ is not altered during ARM bout activity or interbout intervals in $\mathrm{V} 2 \mathrm{a}-\left(\mathrm{G}_{\mathrm{i}}\right) \mathrm{DREADD}$ mice treated with CNO. Thus, diaphragm function at rest does 
not appear to be impaired by silencing V2a neurons, although we cannot rule out a role for $\mathrm{V} 2 \mathrm{a}$ neurons in modulating diaphragm activity during exercise, cough, or other behaviors. We do not think that this result is due to our inability to detect changes in diaphragm activity as we clearly see changes in diaphragm RMS ${ }^{\text {peak }}$ during sighs and following nasal occlusion, behaviors that require higher force generation by the diaphragm (Mantilla et al., 2011). We observed no changes in the frequency of sighs or arousals from sleep, as would be expected if animals experienced hypoxia or hypercapnia, and no changes in ventilation immediately preceding ARM activity. Thus, although we cannot rule out subtle changes in diaphragm function that are not detectable by our methods, it is unlikely that increased ARM activity is secondary to diaphragm impairment caused by silencing V2a neurons.

Another potential mechanism leading to ARM recruitment could be an increase in respiratory drive caused by silencing V2a neurons. We do, in fact, observe changes in ventilation even during periods in which ARMs are not active that are consistent with changes in the activity of brainstem respiratory networks, namely a higher frequency of breathing, shorter $\mathrm{T}_{\mathrm{i}}$ and increased $\mathrm{V}_{\mathrm{T}} / \mathrm{T}_{\mathrm{i}}$ (an indicator of neural ventilatory drive). A higher PIF appears to compensate for the shorter $\mathrm{T}_{\mathrm{i}}$ to maintain $\mathrm{V}_{\mathrm{T}}$. We see an even greater increase in $\mathrm{f}, \mathrm{PIF}$, and $\mathrm{V}_{\mathrm{T}} / \mathrm{T}_{\mathrm{i}}$ during $A R M$ activity compared to interbout intervals, as well as an increase in $\mathrm{V}_{\mathrm{T}}$ (as expected when ARMs are recruited). However, it is not clear from these experiments if the ventilatory changes are due to direct actions of V2a neurons on brainstem respiratory centers or the result of chemosensory or sensory feedback. Despite the changes in respiratory timing, the phrenic motor neurons appear to receive similar levels of overall drive because we observe no detectable change in peak diaphragm activity when V2a neurons are silenced. Moreover, the peak diaphragm activity does not change even when ARMs become active, suggesting that the increased ARM activity is driven by circuits independent of (or with minimal impact on) diaphragm activity. This concept is consistent with studies in human patients showing that neural drive is not uniform to all inspiratory muscles, and may include inspiratory, expiratory and tonic components differentially distributed across motor neuron pools (Butler, 2007; Butler et al., 2014).

A previous study demonstrated that increasing the excitability of V2a neurons is able to activate ARMs (Romer et al., 2017). To explain our findings that either increasing or decreasing V2a excitability can increase ARM activity, we hypothesize that a distinct subset of $\mathrm{V} 2 \mathrm{a}$ neurons promotes ARM activity (i.e., during exercise) whereas another distinct subset inhibits ARM activity at rest (i.e., to prevent activation when they are not needed). An inhibitory pathway for ARMs may serve to reduce unnecessary (and energetically expensive) respiratory muscle activity during behaviors that require low force generation when diaphragm activity is sufficient. The reticulospinal system provides another example where different subsets of V2a neurons appear to produce distinct effects on motor activity. Activating V2a neurons in the rostral medulla can halt ongoing locomotion, indicating that these neurons inhibit locomotor circuits (Bouvier et al., 2015). On the other hand, ablating V2a neurons prevents initiation of fictive locomotion following stimulation of the caudal medulla in a neonatal brainstem-spinal cord preparation, indicating that caudal medullary or spinal V2a are important for activating locomotor circuits (Crone et al., 2008). Further, even within spinal locomotor circuits, different molecularly defined subsets of V2a neurons appear to have different roles in controlling locomotion. For example, Shox $2^{+} / \mathrm{Ch} \times 10^{+} \mathrm{V} 2 \mathrm{a}$ neurons provide excitatory drive to ipsilateral limb motor neurons important for maintaining consistent motor output whereas Shox2/Chx10 ${ }^{+} \mathrm{V} 2 \mathrm{a}$ neurons have connections to inhibitory commissural neurons that maintain alternation of left and right sides at high locomotor speeds (Dougherty et al., 2013; Rybak et al., 2015). An alternative hypothesis is that silencing V2a neurons induces a compensatory change in downstream neurons (i.e., respiratory motor neurons) which renders them more excitable to other inputs, leading to ARM activation. Distinguishing between these two possibilities would require identifying specific $V 2$ a subsets that only activate ARMs when silenced but not activated (or vice versa) or demonstrating that either silencing or inhibiting the same pre-motor V2a neurons could activate ARMs.

An important limitation of this study is that our mouse model targets V2a neurons in both the brainstem and spinal cord, two populations that likely play different roles in the control of breathing. Crone et al. (2012) suggested that V2a neurons in the medulla provide excitatory drive necessary for respiratory rhythm generation, since pontine and spinal cord neurons are not present in the transverse medullary slice preparation used in some experiments. However, they did not rule out additional roles for pontine or spinal V2a neurons, and neither do the experiments reported here. Additional studies using transverse medullary slices or pontomedullary preparations from neonatal V2a- $\left(G_{i}\right) D R E A D D$ mice could further test the importance of brainstem V2a neurons for respiratory rhythm generation as well as investigate the mechanism(s) by which excitatory drive from these neurons promotes frequent, regular inspiratory burst activity. Preparations from older animals could be used to further investigate whether V2a neurons have a less significant impact on inspiratory rhythm generating networks at older ages or whether other neurons/structures compensate for the loss of excitatory drive from V2a neurons. We hypothesize that spinal V2a neurons may be responsible for patterning respiratory motor output, including control of ARM activity. However, we cannot rule out a role for brainstem neurons, such as reticulospinal V2a neurons, in either promoting or inhibiting ARM activity. Future experiments using viruses to target excitatory or inhibitory DREADDs to only cervical V2a neurons or only specific brainstem regions could map the location of $\mathrm{V} 2 \mathrm{a}$ neurons controlling ARM activity. Likewise, intersectional genetic approaches that require Cre and FIp recombinases to drive DREADD expression (Ray et al., 2011) could be used to target only subsets of spinal or brainstem V2a neurons to test their roles in controlling respiratory rhythm and pattern. A bet- 
ter grasp of what different subtypes of V2a neurons do within respiratory circuits will advance our understanding of how spinal and brainstem circuits regulate breathing.

Our findings suggest that approaches to either activate or inhibit V2a neurons could increase ARM activity and enhance respiration in patients with neuromuscular disease or spinal cord injury. The best therapeutic approach (activation or inhibition) may depend on which subset of V2a neurons is targeted, as well as assessing the potential for undesirable side effects. Future experiments targeting subpopulations of V2a neurons in different regions of the brainstem and spinal cord and/or with different transcriptional profiles may help resolve the distinct roles of different V2a subtypes and facilitate identifying therapeutic targets to improve breathing.

\section{References}

Azim E, Jiang J, Alstermark B, Jessell TM (2014) Skilled reaching relies on a V2a propriospinal internal copy circuit. Nature 508:357363.

Bennett JR, Dunroy HM, Corfield DR, Hart N, Simonds AK, Polkey MI, Morrell MJ (2004) Respiratory muscle activity during REM sleep in patients with diaphragm paralysis. Neurology 62:134-137.

Bouvier J, Caggiano V, Leiras R, Caldeira V, Bellardita C, Balueva K, Fuchs A, Kiehn O (2015) Descending command neurons in the brainstem that halt locomotion. Cell 163:1191-1203.

Butler JE (2007) Drive to the human respiratory muscles. Respir Physiol Neurobiol 159:115-126.

Butler JE, Hudson AL, Gandevia SC (2014) The neural control of human inspiratory muscles. Prog Brain Res 209:295-308.

Crone SA, Quinlan KA, Zagoraiou L, Droho S, Restrepo CE, Lundfald L, Endo T, Setlak J, Jessell TM, Kiehn O, Sharma K (2008) Genetic ablation of V2a ipsilateral interneurons disrupts left-right locomotor coordination in mammalian spinal cord. Neuron 60:70-83.

Crone SA, Zhong G, Harris-Warrick R, Sharma K (2009) In mice lacking V2a interneurons, gait depends on speed of locomotion. J Neurosci 29:7098-7109.

Crone SA, Viemari JC, Droho S, Mrejeru A, Ramirez JM, Sharma K (2012) Irregular breathing in mice following genetic ablation of V2a neurons. J Neurosci 32:7895-7906.

Del Negro CA, Koshiya N, Butera RJ Jr., Smith JC (2002) Persistent sodium current, membrane properties and bursting behavior of pre-botzinger complex inspiratory neurons in vitro. J Neurophysiol 88:2242-2250.

Del Negro CA, Funk GD, Feldman JL (2018) Breathing matters. Nat Rev Neurosci 19:351-367.

Denavit-Saubié M, Kalia M, Pierrefiche O, Schweitzer P, Foutz AS, Champagnat J (1994) Maturation of brain stem neurons involved in respiratory rhythmogenesis: biochemical, bioelectrical and morphological properties. Biol Neonate 65:171-175.

Di Pasquale E, Tell F, Monteau R, Hilaire G (1996) Perinatal developmental changes in respiratory activity of medullary and spinal neurons: an in vitro study on fetal and newborn rats. Brain Res Dev Brain Res 91:121-130.

Dick TE, Dutschmann M, Feldman JL, Fong AY, Hulsmann S, Morris KM, Ramirez JM, Smith JC; Respiratory Neurobiology Consortium (2018) Facts and challenges in respiratory neurobiology. Respir Physiol Neurobiol 258:104-107.

Doi A, Ramirez JM (2008) Neuromodulation and the orchestration of the respiratory rhythm. Respir Physiol Neurobiol 164:96-104.

Dougherty KJ, Zagoraiou L, Satoh D, Rozani I, Doobar S, Arber S, Jessell TM, Kiehn O (2013) Locomotor rhythm generation linked to the output of spinal shox2 excitatory interneurons. Neuron 80: 920-933.

Dubois CJ, Cardoit L, Schwarz V, Markkanen M, Airaksinen MS, Uvarov P, Simmers J, Thoby-Brisson M (2018) Role of the K(+)-
$\mathrm{Cl}(-)$ cotransporter $\mathrm{KCC} 2 \mathrm{a}$ isoform in mammalian respiration at birth. eNeuro 5:ENEURO.0264-18.2018.

Dutschmann M, Dick TE (2012) Pontine mechanisms of respiratory control. Compr Physiol 2:2443-2469.

Dutschmann M, Mörschel M, Kron M, Herbert H (2004) Development of adaptive behaviour of the respiratory network: implications for the pontine Kolliker-Fuse nucleus. Respir Physiol Neurobiol 143: 155-165.

Gray PA (2013) Transcription factors define the neuroanatomical organization of the medullary reticular formation. Front Neuroanat 7:7.

Gray PA, Rekling JC, Bocchiaro CM, Feldman JL (1999) Modulation of respiratory frequency by peptidergic input to rhythmogenic neurons in the preBötzinger complex. Science 286:1566-1568.

Guyenet PG, Bayliss DA (2015) Neural control of breathing and CO2 homeostasis. Neuron 87:946-961.

Hayashi M, Hinckley CA, Driscoll SP, Moore NJ, Levine AJ, Hilde KL, Sharma K, Pfaff SL (2018) Graded arrays of spinal and supraspinal V2a interneuron subtypes underlie forelimb and hindlimb motor control. Neuron 97:869-884.e5.

Hilaire G, Duron B (1999) Maturation of the mammalian respiratory system. Physiol Rev 79:325-360.

Hilaire G, Viemari JC, Coulon P, Simonneau M, Bévengut M (2004) Modulation of the respiratory rhythm generator by the pontine noradrenergic A5 and A6 groups in rodents. Respir Physiol Neurobiol 143:187-197.

Hübner CA, Stein V, Hermans-Borgmeyer I, Meyer T, Ballanyi K, Jentsch TJ (2001) Disruption of KCC2 reveals an essential role of $\mathrm{K}-\mathrm{Cl}$ cotransport already in early synaptic inhibition. Neuron 30: 515-524.

Jensen VN, Romer SH, Turner SM, Crone SA (2017) Repeated measurement of respiratory muscle activity and ventilation in mouse models of neuromuscular disease. $J$ Vis Exp. Advance online publication. Retrieved April 17, 2017. doi: 10.3791/55599.

Johnson RA, Mitchell GS (2013) Common mechanisms of compensatory respiratory plasticity in spinal neurological disorders. Respir Physiol Neurobiol 189:419-428.

Mantilla CB, Seven YB, Hurtado-Palomino JN, Zhan WZ, Sieck GC (2011) Chronic assessment of diaphragm muscle EMG activity across motor behaviors. Respir Physiol Neurobiol 177:176-182.

Morgan BJ, Adrian R, Bates ML, Dopp JM, Dempsey JA (2014) Quantifying hypoxia-induced chemoreceptor sensitivity in the awake rodent. J Appl Physiol 117:816-824.

Okabe A, Shimizu-Okabe C, Arata A, Konishi S, Fukuda A, Takayama C (2015) KCC2-mediated regulation of respiration-related rhythmic activity during postnatal development in mouse medulla oblongata. Brain Res 1601:31-39.

Oku Y, Masumiya H, Okada Y (2007) Postnatal developmental changes in activation profiles of the respiratory neuronal network in the rat ventral medulla. J Physiol 585:175-186.

Ray RS, Corcoran AE, Brust RD, Kim JC, Richerson GB, Nattie E, Dymecki SM (2011) Impaired respiratory and body temperature control upon acute serotonergic neuron inhibition. Science 333: 637-642.

Richter DW, Smith JC (2014) Respiratory rhythm generation in vivo. Physiology (Bethesda) 29:58-71.

Romer SH, Seedle K, Turner SM, Li J, Baccei ML, Crone SA (2017) Accessory respiratory muscles enhance ventilation in ALS model mice and are activated by excitatory V2a neurons. Exp Neurol 287:192-204.

Rybak IA, Dougherty KJ, Shevtsova NA (2015) Organization of the mammalian locomotor CPG: review of computational model and circuit architectures based on genetically identified spinal interneurons(1,2,3). eNeuro 2:ENEURO.0069-15.2015.

Sheikhbahaei S, Gourine AV, Smith JC (2017) Respiratory rhythm irregularity after carotid body denervation in rats. Respir Physiol Neurobiol 246:92-97.

Sieck GC, Gransee HM (2012) Respiratory muscles: structure, function and regulation. Lexington, KY: Morgan \& Claypool Life Sciences. 
Thaler J, Harrison K, Sharma K, Lettieri K, Kehrl J, Pfaff SL (1999) Active suppression of interneuron programs within developing motor neurons revealed by analysis of homeodomain factor HB9. Neuron 23:675-687.

Ueno M, Nakamura Y, Li J, Gu Z, Niehaus J, Maezawa M, Crone SA, Goulding M, Baccei ML, Yoshida Y (2018) Corticospinal circuits from the sensory and motor cortices differentially regulate skilled movements through distinct spinal interneurons. Cell Rep 23:1286-1300.e7.

Urban DJ, Roth BL (2015) DREADDs (designer receptors exclusively activated by designer drugs): chemogenetic tools with therapeutic utility. Annu Rev Pharmacol Toxicol 55:399-417.

Viemari JC, Garcia AJ 3rd, Doi A, Ramirez JM (2011) Activation of alpha-2 noradrenergic receptors is critical for the generation of fictive eupnea and fictive gasping inspiratory activities in mammals in vitro. Eur J Neurosci 33:2228-2237.

Wong-Riley MT, Liu Q (2008) Neurochemical and physiological correlates of a critical period of respiratory development in the rat. Respir Physiol Neurobiol 164:28-37.

Zholudeva LV, Karliner JS, Dougherty KJ, Lane MA (2017) Anatomical recruitment of spinal V2a interneurons into phrenic motor circuitry after high cervical spinal cord injury. J Neurotrauma 34: 3058-3065.

Zhu H, Aryal DK, Olsen RH, Urban DJ, Swearingen A, Forbes S, Roth BL, Hochgeschwender U (2016) Cre-dependent DREADD (designer receptors exclusively activated by designer drugs) mice. Genesis 54:439-446. 